\title{
A combined structural and seasonal approach to assess wildfire susceptibility and hazard in summertime
}

\author{
Rafaello Bergonse $^{1} \mathbb{D}$. Sandra Oliveira ${ }^{1} \cdot$ Ana Gonçalves $^{1} \cdot$ Sílvia Nunes $^{2}$. \\ Carlos da Câmara ${ }^{2}$. José Luis Zêzere ${ }^{1}$
}

Received: 23 July 2020 / Accepted: 19 January 2021 / Published online: 9 February 2021

(c) The Author(s) 2021

\begin{abstract}
Wildfire susceptibility and hazard models based on drivers that change only on a multiyear timescale are considered of a structural nature. They ignore specific short-term conditions in any year and period within the year, especially summer, when most wildfire damage occurs in southern Europe. We investigate whether the predictive capacity of structural wildfire susceptibility and hazard models can be improved by integrating a seasonal dimension, expressed by three variables with yearly to seasonal timescales: (1) a meteorological index rating fuel flammability at the onset of summer; (2) the scarcity of fuel associated with the burned areas of the previous year, and (3) the excessive abundance of fuel in especially fire-prone areas that have not been burned in the previous ten years. We describe a new methodology for combining the structural maps with the seasonal variables, producing year-specific seasonal susceptibility and hazard maps. We then compare the structural and seasonal maps as to their capacity to predict burnt areas during the summer period in a set of eight independent years. The seasonal maps revealed a higher predictive capacity in $75 \%$ of the validation period, both for susceptibility and hazard, when only the highest class was considered. This percentage was reduced to $50 \%$ when the two highest classes were considered together. In some years, structural factors and other unconsidered variables probably exert a strong influence over the spatial pattern of wildfire incidence. These findings can complement existing structural data and improve the mapping tools used to define wildfire prevention and mitigation actions.
\end{abstract}

Keywords Wildfire susceptibility $\cdot$ Hazard assessment $\cdot$ Structural approach $\cdot$ Seasonal variables $\cdot$ Portugal

\section{Introduction}

Portugal is one of the southern European countries most affected by wildfires. Data on wildfire incidence and damage for the top affected ones (Portugal, Spain, France, Italy, Greece) show that, from 1980 to 2018, and despite having the smallest territory, Portugal

Rafaello Bergonse

rafaellobergonse@campus.ul.pt

Extended author information available on the last page of the article 
has the highest average number of annual fires and the second largest annual burnt area, second only to Spain (San-Miguel-Ayanz, Durrant, Boca, Libertá, Branco, De Rigo, Ferrari, Maianti, Artes Vivancos, Pfeiffer, Loffler, Nuijten, Leray and Jacome Felix Oom, 2019). Most of this damage takes place during the summer months and results from a relatively small number of large fires (Pereira et al. 2005, 2006,2011; San-Miguel-Ayanz et al. 2013a). Wildfire is a complex phenomenon that is driven by several factors. These include the availability of fuel, its spatial continuity and flammability, the occurrence of ignitions, the speed of flame propagation, but also the availability of firefighting resources and the ease of access to the burning areas (Moreira et al. 2011; Viegas 2006). A way to deal with this complexity is to focus on two of the facets of the phenomenon: (1) the relations, analyzed throughout a multiyear period, between annual burnt areas and predisposing factors inherent to the territory, such as land cover or hillslope inclination; (2) the tendency for wildfire to repeatedly affect a given area through time, expressed as its probability of occurrence. These two facets are behind the production of wildfire susceptibility and hazard maps, which are well-established tools for supporting wildfire prevention measures and for defining firefighting strategies (Bergonse and Bidarra 2010; Beverly et al. 2009; Leuenberger et al. 2018; Joana Parente and Pereira 2016; Peters et al. 2013; Valdez et al. 2017; Viedma et al. 2009).

Despite their widespread use, the concepts of susceptibility and hazard have been defined rather differently by several authors. For example, Leuenberger et al. (2018) defined wildfire susceptibility as "the probability that fire occurs in a specific area without considering a temporal scale, assessed on the basis of predisposing factors related to terrain's intrinsic characteristics," whereas Cao et al. (2017) defined it simply as the spatial distribution of "the likelihood of suffering harm," thus allowing for factors other than the terrain's intrinsic characteristics (e.g., the simple probability of wildfire occurrence, obtained from the known annual wildfire history). In this research, we adopt the conceptual framework proposed by Verde and Zêzere (2010), itself based on previous work by Varnes (1984) and Bachmann and Allgöwer (1999), and later employed by Joana Parente and Pereira (2016). This same framework has been officially adopted by the Portuguese Civil Protection Authority in its risk mapping guidelines (Julião et al 2009), and by the Portuguese Institute for the Conservation of Nature and Forests (ICNF) in its annual wildfire hazard maps (ICNF 2020). In this approach, wildfire susceptibility is defined as "the terrain's propensity to suffer a wildfire or to support its spreading, given by the terrain's intrinsic characteristics (e.g., elevation, slope, vegetation cover)", whereas wildfire hazard results from the multiplication of the terrain's inherent susceptibility with the probability of wildfire occurrence (Verde and Zêzere 2010). Definitions for these and the other wildfire-related concepts adopted in this work are presented in Table 1.

A salient feature of this conceptual approach, which we will call "structural," is the fact that it is based on variables of a relatively static nature, (e.g., Parente and Pereira 2016; Costafreda-Aumedes et al. 2017). Numerous works have employed structural approaches to wildfire susceptibility and hazard in Europe. These are often based in combinations of environmental variables, typically using different techniques to integrate them with burnt area maps so as to quantify the former's effect in the propensity for a given spatial unit to burn (e.g., a pixel, a province) (Leuenberger et al. 2018; Moreira et al. 2009; Oliveira et al. 2020; Joana Parente and Pereira 2016; Verde and Zêzere 2010). Other authors have employed combinations of environmental and socioeconomic factors (Arpaci et al. 2014; Oliveira et al. 2012; Sebastián-López et al. 2008) or even only the latter (Arndt et al. 2013), to uncover the importance of different wildfire drivers. 


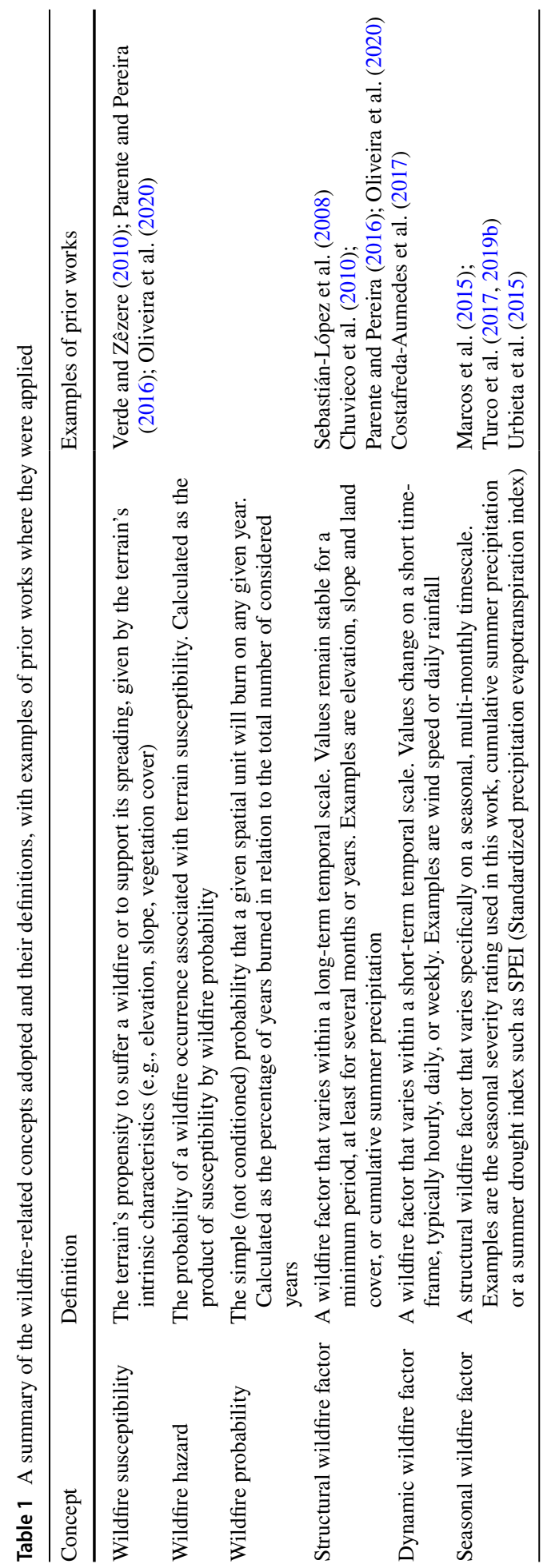


In contrast to structural factors, other wildfire conditions change across shorter timescales. Fuel availability, for example, plays a decisive role on the possibility of occurrence of wildfires. Lasanta et al. (2018) demonstrated how the management of biomass through a program of mechanical removal and grazing resulted in a reduction in annual burnt areas in the north of Spain. Numerous other authors established connections between increased wildfire frequency and magnitude and biomass availability (e.g., Fernandes et al. 2014; Moreira et al. 2001, 2011; Pausas and Fernández-Muñoz 2012). Despite the inherent correlation between land cover and fuel availability, structural approaches ignore biomass availability factors such as the possibility that an area was burnt in the previous year (reducing available biomass), or conversely that it has not been burnt in several years (promoting its accumulation). The water content of fuels, a crucial control of their flammability, is another factor that varies over small timescales and is ignored in structural approaches to wildfire susceptibility and hazard, despite its important role on wildfire severity and occurrence (e.g., Carvalho et al. 2008; Loepfe et al. 2014; Slocum et al. 2010). The same could be said, for example, of wind patterns (speed and direction) (e.g., Lasslop et al. 2015; Weise et al. 2005).

To deal with the complex nature of wildfire conditions, some authors have combined structural and dynamic factors, such as the moisture content of fuels (Chuvieco et al. 2010; López et al. 2002), thus producing susceptibility and hazard maps that change on a daily scale. In other situations, hazard assessment has been done based on specific weather conditions, such as low relative humidity and elevated air temperatures (Botequim et al. 2017; Fernandes et al. 2006; Fernandes 2009), thus focusing on fuel dynamics during the most fire-prone times of the year.

Yet another approach to wildfire susceptibility is to employ structural variables measured on a seasonal timescale, to predict the severity of wildfires during a later period. These are the cases of Nunes et al. (2014, 2019) and Pereira et al. (2013), who used a cumulative sum of the values of daily severity rating (DSR), obtained through a transformation of the fire weather index (FWI) (Van Wagner 1987). This cumulative index characterizes the moisture state of vegetation during the prefire season (spring to early summer), to predict the severity of wildfires during the ensuing summer period. This approach has an explicit predictive component, since values of a wildfire factor measured during a given period of the year are used to predict the occurrence of severe wildfires during another, subsequent period.

The objective of this work is to assess the benefits of adding a seasonal wildfire factor, as well as two structural factors that are usually absent from these models, to a wellestablished structural model of wildfire susceptibility and hazard. The results are evaluated in terms of the model's capacity to predict which areas will burn during the three-month period between June 15 and September 15, when most of the annual wildfire damage typically takes place (Calheiros et al. 2020; Pereira et al. 2005). The proposed methodology is innovative in two aspects: firstly, it combines two distinct approaches to assess wildfire susceptibility/hazard: a structural model, and the use of a spring-based seasonal meteorological index to predict wildfire occurrence in the subsequent summer season. Secondly, it employs two structural factors representing fuel patterns that are typically absent from structural models: the lack of fuel due to the previous year's wildfires, and the overabundance of fuel resulting from the absence of wildfires for a multi-year period.

The methodology is straightforward and applicable to the structural susceptibility and hazard maps that are used by the state authorities for the Portuguese mainland. Furthermore, it can be easily applied to other susceptibility or hazard models in a Mediterranean climatic context, with comparable effects regarding the seasonal wildfire occurrence. 


\section{Data and methods}

As a starting point, we employed the structural susceptibility and hazard models proposed by Oliveira et al. (2020), which have produced good results and have been adopted by the Portuguese Institute for the Conservation of Nature and Forests (ICNF). Each of these models was used to produce structural wildfire susceptibility and hazard maps using annual burnt area data for the period 1975-2011. These maps were then combined with a set of seasonal or yearly variables referring to each of the 8 years between 2012 and 2019, thus producing susceptibility and hazard maps which include a seasonal time scale for each of these years, herein designated as seasonal susceptibility and hazard maps. In accordance with this approach, the seasonal susceptibility and hazard maps result from the combination of multiple components with contrasting temporal scopes, as illustrated in Fig. 1. A 25-m pixel size was adopted for all spatial data.

For any given year and any given spatial unit, i.e., pixel, the seasonal dimension of wildfire susceptibility and hazard was expressed by three variables. The first is the scarcity of fuel, represented by the condition of having been burnt in the previous year, thus assuming that such areas will be less fire-prone.

The second seasonal variable integrated was the relative abundance of fuel, conducive to a high propensity for burning. This applies only to areas of high and very high structural susceptibility (when calculating seasonal susceptibility) or structural hazard (for seasonal hazard). This factor was expressed by the condition of not having burnt in the previous ten years. To focus attention on those areas with potential for wildfires of high severity and destructiveness, results were narrowed down to continuous extensions with a minimum of 500 hectares.

The third seasonal variable incorporated was the meteorologically induced flammability of vegetation at the onset of summer, as rated by an index that integrates meteorological conditions along spring (April 1-June 15), obtained from one of the components of the

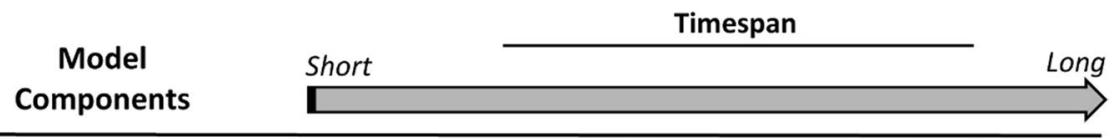

\begin{tabular}{|l|}
\hline $\begin{array}{l}\text { Structural susceptibility } \\
\text { /hazard }\end{array}$ \\
\hline $\begin{array}{l}\text { Fuel overabundance } \\
\text { Areas of High or Very high } \\
\text { susceptibility/hazard not } \\
\text { burnt during the previous } 10 \\
\text { years } \Rightarrow>500 \text { ha. }\end{array}$ \\
\hline
\end{tabular}

\section{Fuel scarcity \\ Areas burnt the previous year.}

Summer fuel flammability Seasonal Severity Rating (1 Apr - 15 Jun)

Fig. 1 The contrasting temporal scopes of the components of the seasonal susceptibility/hazard maps 
Canadian Forest Fire Weather Index System (CFFWIS) (Van Wagner 1974, 1987), which we call seasonal severity rating (SSR).

\subsection{Structural wildfire susceptibility and hazard}

Wildfire susceptibility and hazard maps were produced using the methodology described by Oliveira et al. (2020) (schematized in Fig. 2), in the form of 25-m resolution raster datasets. For each pixel, susceptibility values are the result of the sum of the likelihood ratios (LR) associated with the variables elevation (in $\mathrm{m}$ ), slope angle (in degrees) and land cover, obtained by cross-tabulating each of these classified variables with past burnt areas. Aspect was not considered, as this variable does not have a clear spatial relationship with burned area in mainland Portugal and has been shown not to increase the predictive capacity of wildfire susceptibility and hazard models (Oliveira et al. 2020).

Topographic data were obtained from the European Environmental Agency's Digital Surface Model, with a 25-m pixel (https://www.eea.europa.eu/data-and-maps/data/coper nicus-land-monitoring-service-eu-dem). Land cover data were obtained from the Portuguese General-Directorate of the Territory (Direção-Geral do Território).

For each class $i$ of each variable, the LR score Lri is calculated as (Lee 2004):

$$
L r i=\frac{S i / S}{N i / N}
$$

where $S i$ is the number of burnt terrain units (pixels) corresponding to class $i$ of variable $Y, S$ is the number of burnt terrain units, $N i$ is the number of terrain units associated with class $i$ of variable $Y$, and $N$ is the total number of terrain units. For a total of $n$ predisposing variables, the total LR score of each terrain unit $(L r j)$ is calculated as:

$$
L r j=\sum_{i=1}^{n} X i j . L r i
$$

where $X i j$ equals 1 for the classes of the variables that are present and 0 for all others.

Yearly burnt areas between 1975 and 2011 were used to derive LR scores for elevation and slope angle. As land cover mapping is only available since 1995, with maps existing for 1995, 2007 and 2010 within the modeling period, LR scores were calculated for each class considering the specific timeframe represented by each land cover map. Likelihood ratio scores were, therefore, calculated for the 1995 map using annual burnt areas for the years 1995-2006 (12 years), for the 2007 map using annual burnt areas for the years 2007-2009 (3 years), and for the 2010 map using annual burnt areas for the years 2010-2011 (2 years). The final LR score for each land cover class was calculated as the weighted average of the scores within the successive land cover maps, with the number of years covered by each map used as weight.

Areas burnt between 1975 and 2011 are shown in Fig. 3. The elevation, slope angle and land cover maps used are shown in Figs. 4 and 5.

It is noteworthy that the maps of yearly burnt areas used to produce the structural maps do not discriminate the exact date of occurrence of each wildfire. This implies that at least a part of the wildfires does not correspond to the summer wildfires which these maps are intended to predict. This was unavoidable because, in Portugal, state-produced burnt area mapping only discriminates the date of occurrence of wildfires since 2012. 


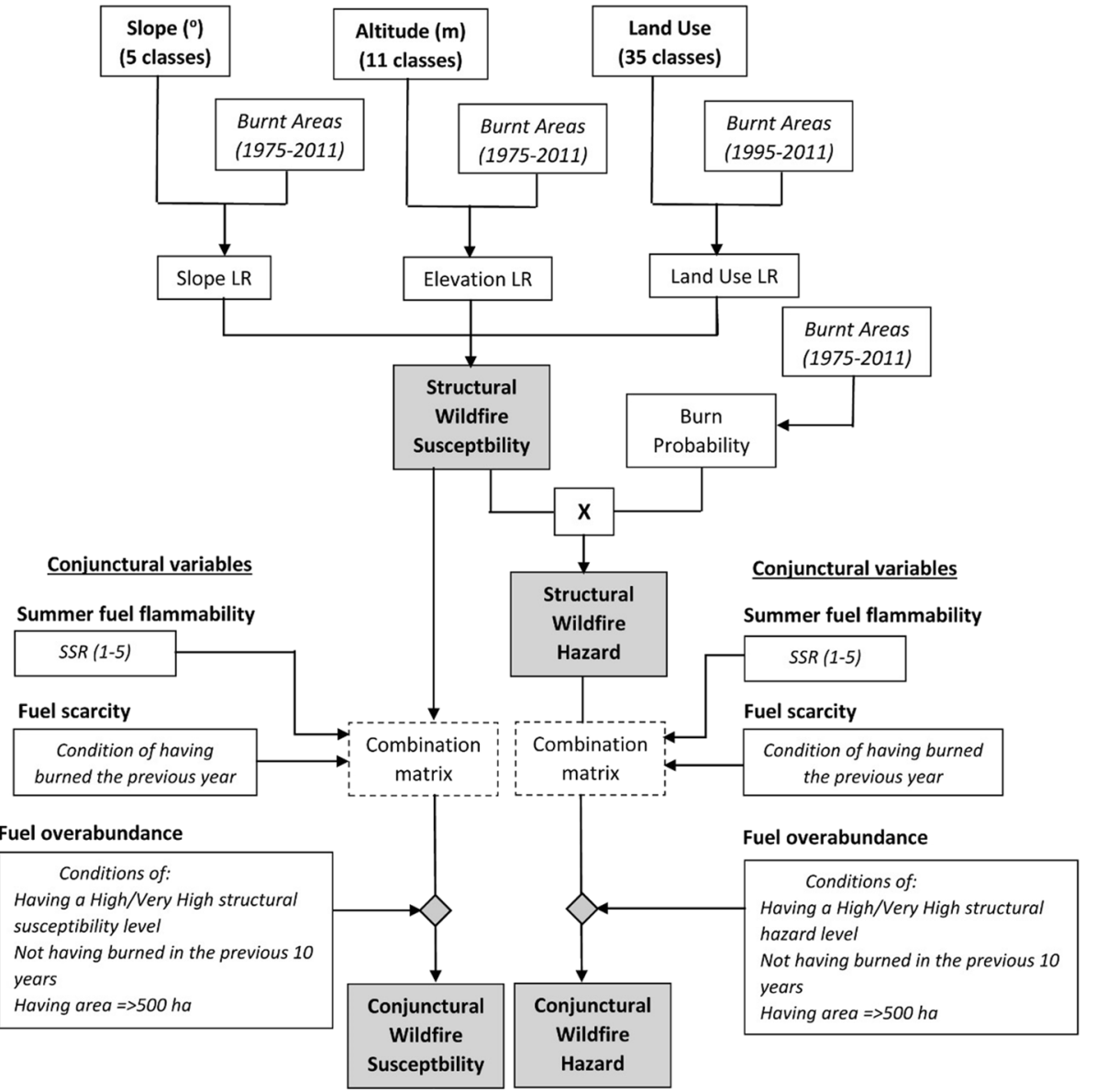

Fig. 2 A schematic representation of the methodology used to produce the structural and seasonal wildfire susceptibility and hazard maps

Wildfire hazard was obtained by multiplying the susceptibility score of each pixel by its probability of burning each year, obtained as the ratio of times that pixel was burnt, between 1975 and 2011, and the total number of years of this period (37 years).

In accordance with the existing Portuguese law, wildfire hazard maps should be classified into five classes (Very Low; Low; Medium; High; Very High) (Law Decree 124/2006, of June 28, art. 5). We used quintiles as a classification criterion, following the usual practice of the Portuguese Institute for the Conservation of Nature and Forests (ICNF) in its annual wildfire hazard maps.

\subsection{Seasonal variables}

Seasonal susceptibility and hazard maps were created for each year of the validation period (2012-2019), using a set of variables that represent year or sub-year conditions, in combination with the structural maps. This period, different from the modeling one 
Fig. 3 Areas burnt between 1975 and 2011, expressed as number of times burnt. Source of data: ICNF

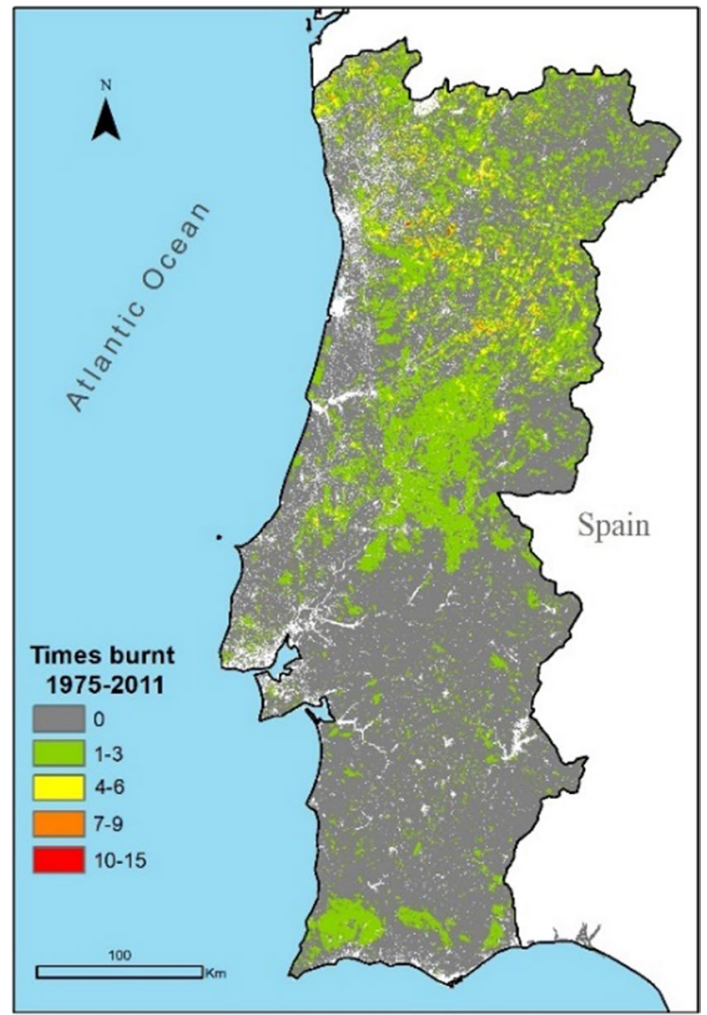

to ensure independent validation, corresponds to that in which state-produced burnt area maps discriminating the date of occurrence of wildfires are available.

\subsubsection{Fuel scarcity-areas burnt in the preceding year}

The areas burnt in the previous year were obtained from the annual burnt area maps, made available in vector format by the National Forest Services (ICNF). All annual maps were converted to raster format ( $25 \mathrm{~m}$ resolution), with burnt pixels having the value 1 , or otherwise 0 .

\subsubsection{Fuel overabundance-high or very high wildfire susceptibility/hazard areas that did not burn in the previous 10 years, with area equal to or larger than 500 ha}

For each of the eight validation years, annual burnt area maps expressed as 1 (burnt) and 0 (nor burnt) for the preceding 10 years were summed. The resulting maps were 

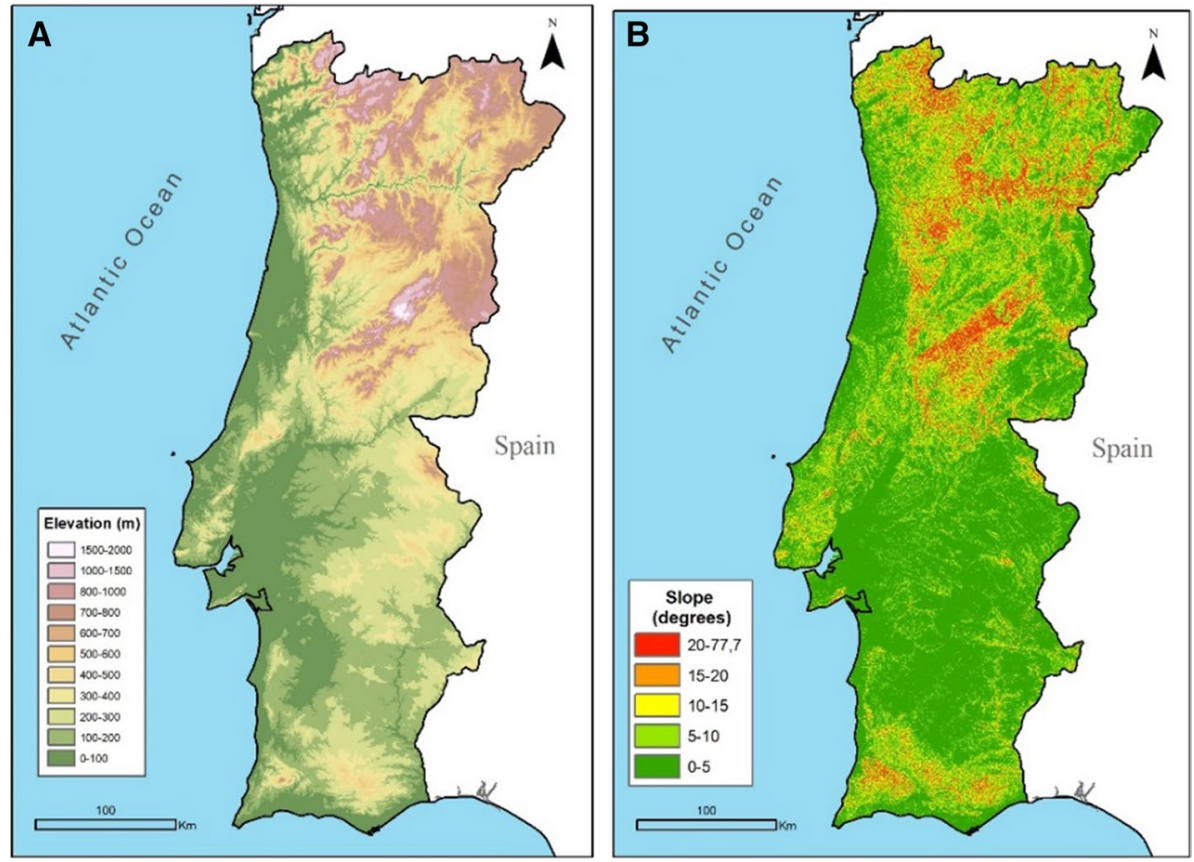

Fig. 4 Elevation (A) and slope angle (B). Source of data: https://www.eea.europa.eu/data-and-maps/data/ copernicus-land-monitoring-service-eu-dem
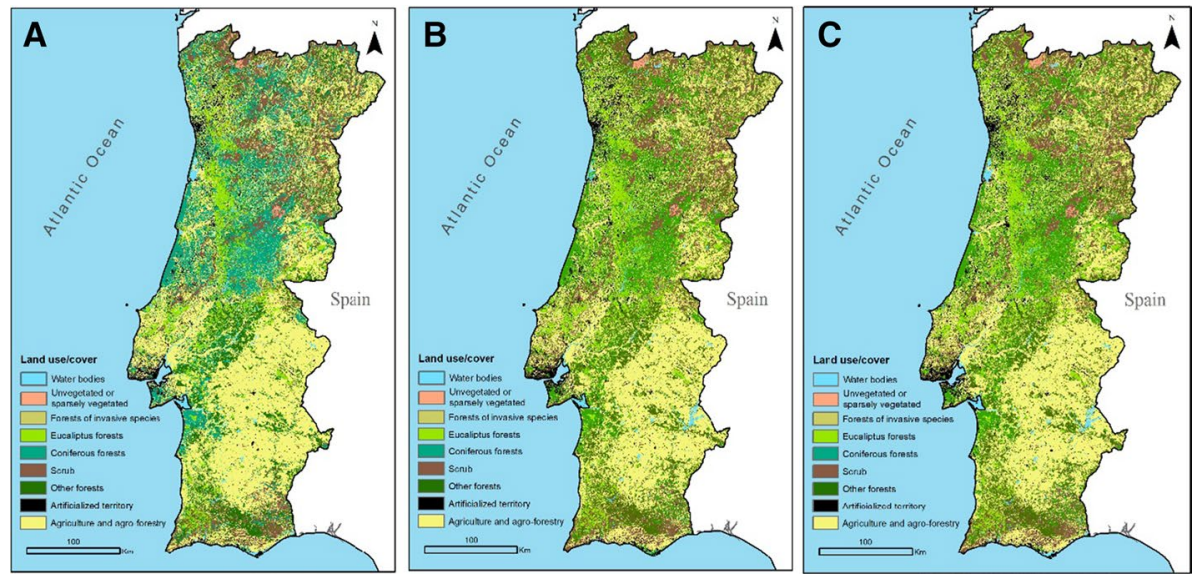

Fig. 5 Land cover in 1995 (A), 2007 (B) and 2010 (C). Source: Direção-Geral do Território

reclassified, with pixels that did not burn during the previous ten years being given the value 1 , and all others 0 . The structural susceptibility and hazard maps were reclassified to produce new maps in which the pixels in the two highest classes (High and Very High) were given the value 1 , and all the others 0 . 
For each validation year, the map identifying the pixels in the two highest classes of susceptibility/hazard was summed with the map representing the unburnt pixels in the previous ten years. The result was a map varying between 0 (pixels burnt in the previous ten years and not belonging to the two highest susceptibility/hazard classes) and 2 (pixels unburnt in the previous ten years and belonging to the two highest classes). The latter were reclassified as 1 , and all the others were reclassified as 0 . We then aggregated all connected pixels in this map into regions. A pixel was considered connected to another if both were adjacent, either in a vertical, a horizontal or diagonal orientation. A region was defined as an area with at least 8000 connected unburnt pixels (500 ha).

\subsubsection{Meteorologically induced summer fuel flammability-seasonal severity rating}

For each of the years between 1995 and 2019, the seasonal severity rating (SSR) was calculated as the cumulative sum of the values of daily severity rating (DSR), from April 1 to June 15. The DSR is obtained through a simple transformation of the fire weather index (FWI) (Van Wagner 1987), and considered more suitable to be cumulated or averaged (Nunes et al. 2019). Although the DSR is meant to express the difficulty in controlling wildfire, an elevated cumulative value in the months preceding the summer season indicates the prevalence of relatively high temperatures and low rainfall, which will, in turn, promote water and thermal stress in vegetation in summertime, making it more prone to burning. The main advantage of this predictive use of spring/early summer cumulative DSR values is that it allows knowing, ahead of the summer, if the vegetation will be more fire-prone due to the weather effects on water content. This approach has been used by Pereira et al. (2013), Nunes et al. (2014) and Nunes et al. (2019) to anticipate the severity of summer wildfires.

Annual SSR maps were computed from gridded daily values at 12:00 UTC of $2 \mathrm{~m}$ temperature, relative humidity, wind speed and 24 h-cumulated precipitation, obtained from the ERA-Interim reanalysis dataset (Dee et al. 2011), issued by the European Centre for Medium-Range Weather Forecasts (ECMWF). The ERA-Interim data were then re-projected into the normalized geostationary projection (NGP) of Meteosat Second Generation (MSG) (EUMETSAT 1999), with an average pixel size of about $4 \mathrm{~km} \times 4 \mathrm{~km}$ over Portugal. Details about the procedure may be found in Pinto et al. (2018). Finally, the gridded values of SSR were interpolated into the $25 \mathrm{~m}$-pixels of the study area.

Each annual map between 2012 and 2019 was then reclassified as an anomaly, calculated in relation to the mean SSR representing the period between 1995 and that specific year. For example, the SSR for each pixel in 2012 was calculated as:

Anomaly $[$ SSR2012] $=[$ SSR2012-Mean $($ SSR1995 - SSR2012) $] /$ Mean $($ SSR1995 - SSR2012)

Finally, each of the annual SSR anomaly maps for the validation period 2012-2019 was classified in five levels using quintiles.

\subsection{Calculation of seasonal wildfire susceptibility and hazard}

The seasonal wildfire susceptibility and hazard maps were obtained by combining the structural maps with the seasonal variables, for each year of the validation period (2012-2019). For each year, we crossed the structural maps with the SSR map (classified from 1 to 5) and with the map describing the condition of having burnt the previous 


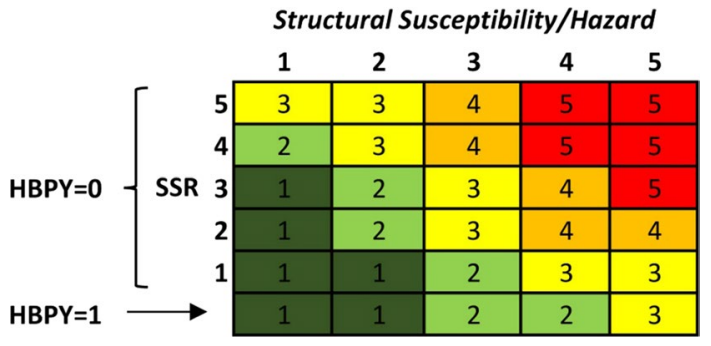

Fig. 6 Matrix used for combining the structural susceptibility and hazard maps with meteorologically induced summer fuel flammability, expressed by the seasonal severity rating (SSR) and with the condition of having burnt the previous year $(\mathrm{HBPY}=1)$ or otherwise $(\mathrm{HBPY}=0)$. The result of this integration of data was a map with values from 1 to 5 . HBPY was given priority over SSR because of its fundamental control over the availability of fuel

year (coded as 1) versus having not burnt (coded as 0 ). This procedure was performed in accordance with the relations expressed in the matrix in Fig. 6, in which the final value associated with any given pixel (from 1 to 5) depends on the combination of its structural susceptibility or hazard class with two elements: i) its SSR class and ii) the condition of having burned the previous year (HBPY), the latter having priority over SSR. For example, if a given pixel did not burn in the previous year $(\mathrm{HBPY}=0)$, has a structural susceptibility/hazard class of 2 and a SSR class of 4, it will be reclassified as 3. However, if the same pixel did burn in the previous year $(\mathrm{HBPY}=1)$, it will be reclassified as 1 according to its structural susceptibility/hazard class. The structure of the matrix implies that any pixel that burned the previous year can only acquire values up to 3 , as its propensity for burning will be constrained by a lack of available fuel.

Subsequently, the resulting map was combined with the map expressing the third seasonal variable: fuel overabundance, expressed as continuous areas of at least 500 ha that did not burn in the previous 10 years. This was performed using conditional statements; if a given pixel satisfied this condition, its class was raised by 1 level (up to a maximum of 5), maintaining its original value otherwise. ArcGIS 10.7.1 (ESRI@) was used for all spatial analysis operations.

\subsection{Model evaluation and validation}

Areas burnt between June 15 and September 15 during the 8 years of the validation period were obtained in vector format from ICNF. The minimum continuous recorded burnt area was 5 ha. A synthesis of all areas burnt during the validation period is shown in Fig. 7.

The structural susceptibility and hazard maps were cross-tabulated with each of the eight annual maps of area burnt between June 15 and September 15. Likewise, each seasonal susceptibility and hazard map was cross-tabulated with the summertime burnt area map of the corresponding year. In each case, the percentage of annual burnt area encompassed by the two highest susceptibility/hazard classes was determined.

Besides the criterium of predictive capacity, the structural and seasonal maps were also compared in terms of their ability to incorporate the largest possible burnt area while occupying the least possible total area, i.e., their effectiveness. This criterium was needed since, unlike the quintile-based classes of the structural maps, the classes in the seasonal maps have an unequal size. As such, the effectiveness ratio (EF) (Chung and Fabbri 2003; 
Fig. 7 Summertime wildfire incidence (15 Jul-15 Sep) during the validation period 2012-2019

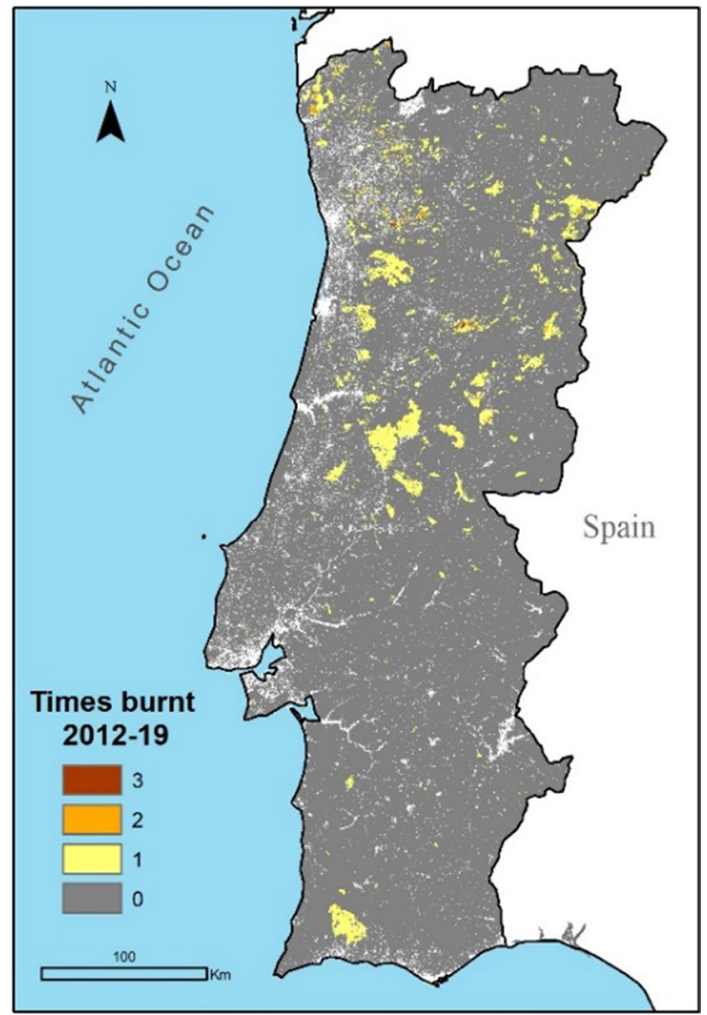

Epifânio et al. 2014) was calculated for the two highest classes in both the structural and seasonal maps. For any given class, this indicator is estimated as:

$\mathrm{EF}=($ Burnt area within class / Total burnt area)/(Total area of class / Total study area)

Afterward, we assessed the effect of each seasonal variable in the predictive ability of the model, specifically if their integration would result in a reduction in the predictive ability of the seasonal model in comparison with the structural one. We focused our attention on fuel scarcity (expressed by the condition of having burnt the previous year) and on the meteorologically induced summer flammability (expressed by the seasonal severity rating, SSR). Fuel overabundance was disregarded, as this variable can only result in increases in the area associated with the two highest seasonal susceptibility/hazard classes. Therefore, its effect can only be either the maintenance or the increase of the burnt area predicted by the two highest classes, not a reduction. To assess the role of fuel scarcity, we calculated for each year of the validation period the percentage of burnt area in the summer that had also burnt in the previous year, by overlapping the fire perimeters of both years. If this seasonal variable were responsible for any decrease in predictive capacity in any of the tested years (considering the two highest susceptibility/hazard classes together), we could expect a somewhat high value in these years, in contrast to all others.

To assess the individual influence of meteorologically induced summer flammability, we cross-tabulated the annual SSR maps with the annual summertime burnt areas for the validation period. If this seasonal variable were responsible for a decrease in predictive 
Table 2 Likelihood Ratio scores (LR) obtained for each elevation class

Table 3 Likelihood Ratio scores (LR) obtained for each slope angle class

\begin{tabular}{ll}
\hline Elevation $(\mathrm{m})$ & LR \\
\hline $0-100$ & 0.198 \\
$100-200$ & 0.437 \\
$200-300$ & 0.668 \\
$300-400$ & 1.082 \\
$400-500$ & 1.594 \\
$500-600$ & 1.948 \\
$600-700$ & 2.083 \\
$700-800$ & 2.117 \\
$800-1000$ & 2.815 \\
$1000-1500$ & 3.885 \\
$1500-2000$ & 1.519 \\
\hline
\end{tabular}

\begin{tabular}{ll}
\hline Slope angle (o) & LR \\
\hline $0-5$ & 0.442 \\
$5-10$ & 1.221 \\
$10-15$ & 1.938 \\
$15-20$ & 2.396 \\
$>20$ & 2.660 \\
\hline
\end{tabular}

capacity in any of the tested years, we could expect a relatively high concentration of burnt area in the lower SSR classes.

\section{Results and discussion}

\subsection{Structural factors}

Areas with elevation below $300 \mathrm{~m}$ are less fire-prone. Likelihood ratio scores increase progressively for elevation classes from $300 \mathrm{~m}$ until $1500 \mathrm{~m}$ (Table 2). Regarding slope, higher classes show higher favorability toward burned areas (Table 3), with only the first class, up to $5^{\circ}$, showing a LR score below 1 . Land cover classes representing scrub and sparse vegetation have the highest mean LR score, with 2.99 and 4.01, respectively (Table 4), although generally decreasing since 1995. Regarding forested areas, chestnut forests show the highest mean LR score, with a maximum in 1995 (close to 3) and decreasing sharply afterward, to 0.307 in 2010. Eucalyptus, Pinus Pinaster and a subclass of oak (Other Oak forests) forests have LR scores above 1.4. On the contrary, all agricultural areas show low favorability, with LR scores below 1, including agroforests.

The influence of topographic features in wildfire distribution is widely recognized (Calviño-Cancela et al. 2017; Carmo et al. 2011; Nunes et al. 2016; Oliveira and Zêzere, 2020). In Portugal, areas with convoluted terrain have a high fire incidence, expressed also in an increased fire probability, as shown in Fig. 8 for the period 1975-2011. Shrubland (scrub) is a fire-prone land cover type, able to colonize rapidly a burned area 
Table 4 Likelihood Ratio scores obtained for each land cover class

\begin{tabular}{|c|c|c|c|c|}
\hline \multirow[t]{2}{*}{ Land cover categories } & \multicolumn{3}{|l|}{ LR } & \multirow[t]{2}{*}{ Weighted average } \\
\hline & 1995 & 2007 & 2010 & \\
\hline Temporary irrigated crops & 0.103 & 0.201 & 0.139 & 0.125 \\
\hline Temporary dryland crops & 0.211 & 0.399 & 0.198 & 0.243 \\
\hline Temporary crops and/or pastures + olive groves & - & 0.138 & 0.169 & 0.150 \\
\hline Temporary crops and/or pastures + orchards & - & 0.769 & 0.156 & 0.524 \\
\hline Temporary crops and/or pastures + vineyards & - & 0.182 & 0.088 & 0.144 \\
\hline Olive grove & 0.304 & 0.179 & 0.133 & 0.262 \\
\hline Orchards & 0.149 & 0.174 & 0.096 & 0.147 \\
\hline Vineyards & 0.109 & 0.097 & 0.190 & 0.117 \\
\hline Greenhouses/nurseries & - & 0.017 & 0.078 & 0.042 \\
\hline Complex cultivation systems & 0.262 & 0.211 & 0.161 & 0.241 \\
\hline Agriculture + natural and semi-natural spaces & 0.644 & 1.129 & 0.714 & 0.738 \\
\hline Holm oak-based agroforestry & 0.087 & 0.119 & 0.039 & 0.087 \\
\hline Pinus pinea-based agroforestry & 0.091 & 0.001 & 0.078 & 0.074 \\
\hline Cork oak-based agroforestry & 0.192 & 0.051 & 0.064 & 0.152 \\
\hline Cork oak and holm oak-based agroforestry & 0.122 & 0.063 & 0.044 & 0.103 \\
\hline Agroforestry based on other species & 0.569 & 0.788 & 0.340 & 0.581 \\
\hline Agroforestry based on other combinations & 0.308 & 0.039 & 0.027 & 0.227 \\
\hline Agroforestry based on other oaks & 0.573 & 2.030 & 0.564 & 0.829 \\
\hline Pinus Pinaster forests & 1.546 & 1.036 & 1.376 & 1.436 \\
\hline Pinus Pinea forests & 0.255 & 0.217 & 0.195 & 0.241 \\
\hline Cork-oak forests & 0.750 & 0.179 & 0.136 & 0.577 \\
\hline Holm oak forests & 0.469 & 0.665 & 0.213 & 0.474 \\
\hline Chestnut forests & 2.973 & 0.953 & 0.307 & 2.303 \\
\hline Invasive species forests & 0.559 & 1.724 & 0.967 & 0.813 \\
\hline Eucalyptus forests & 1.638 & 0.705 & 1.173 & 1.419 \\
\hline Other broadleaved forests & 0.772 & 2.453 & 1.064 & 1.103 \\
\hline Other coniferous forests & 1.087 & 1.700 & 0.766 & 1.158 \\
\hline Other oak forests & 1.454 & 2.816 & 2.338 & 1.798 \\
\hline Forestry nurseries & - & 0 & 0 & 0 \\
\hline Firebreaks & 0.742 & 0.243 & 1.141 & 0.701 \\
\hline Permanent pastures & 0.438 & 0.306 & 0.113 & 0.377 \\
\hline Natural herbaceous vegetation & - & 1.319 & 0.932 & 1.164 \\
\hline Other woody formations & - & 2.636 & 0.335 & 1.716 \\
\hline Shrub-Scrub & 2.744 & 3.474 & 3.766 & 2.993 \\
\hline Sparse vegetation & 3.457 & 6.019 & 4.322 & 4.011 \\
\hline
\end{tabular}

or abandoned farmland, promoting fuel build-up and increasing hazard levels (Barros \& Pereira, 2014; Carmo et al., 2011; Moreira et al., 2011; Oliveira et al., 2014).

The areas most susceptible to wildfires are located inland in the north and central regions, and also further south in Algarve, mirroring the distribution of the most fireprone classes regarding topography and land cover (Fig. 9A). When combined with 
Fig. 8 Burn probability (1975-2011)

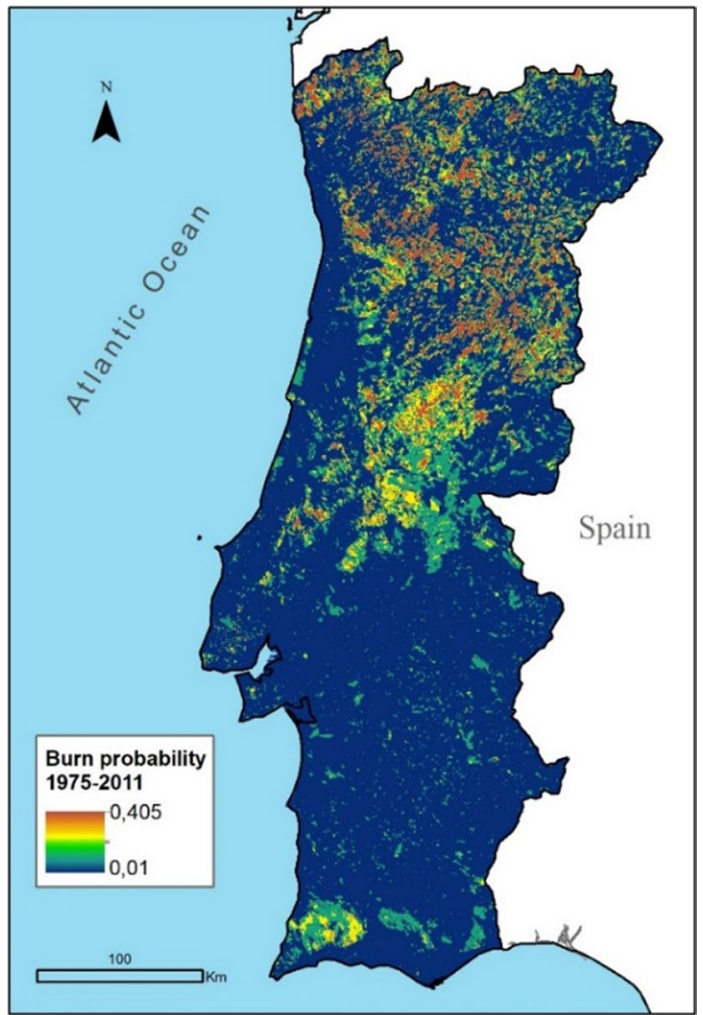

probability to obtain hazard (Fig. 9B), a similar spatial pattern is found overall, but with a stronger distinction of the areas classified as very high.

\subsection{Seasonal factors-the seasonal severity rating}

The weather-related anomaly given by the seasonal severity rating (SSR) is highly variable among the tested years (2012-2019, Fig. 10), illustrating the changeable nature of this factor. In 2012, the areas with stronger anomalies, i.e., where vegetation will likely be drier than usual and more predisposed to burn, are found across central Portugal, whereas in 2013 the highest anomaly spreads along the western coast of the mainland. In 2014, it is the northeast region that shows the higher anomalies, whereas in 2015 the highest anomaly class is found in the northwest region. In 2016, the highest anomalies are centered on the southern half of the territory, changing to the center-south in combination with the extreme southeast in 2017, and to the western coast, together with some of the extreme north, in 2018. In 2019, the highest anomalies show a somewhat dispersed pattern, with concentrations in the southernmost and northeastern regions.

These patterns evidence the differences between the weather conditions recorded in each year and the averaged conditions over a period of at least 18 years, during springtime. The variability of weather conditions along a season or year is pointed out as a major factor for the annual differences in burned area extent (Jolly et al. 2015; Trigo et al. 2016). Years with exceptional weather conditions conducive to higher temperatures, lower humidity, drought 

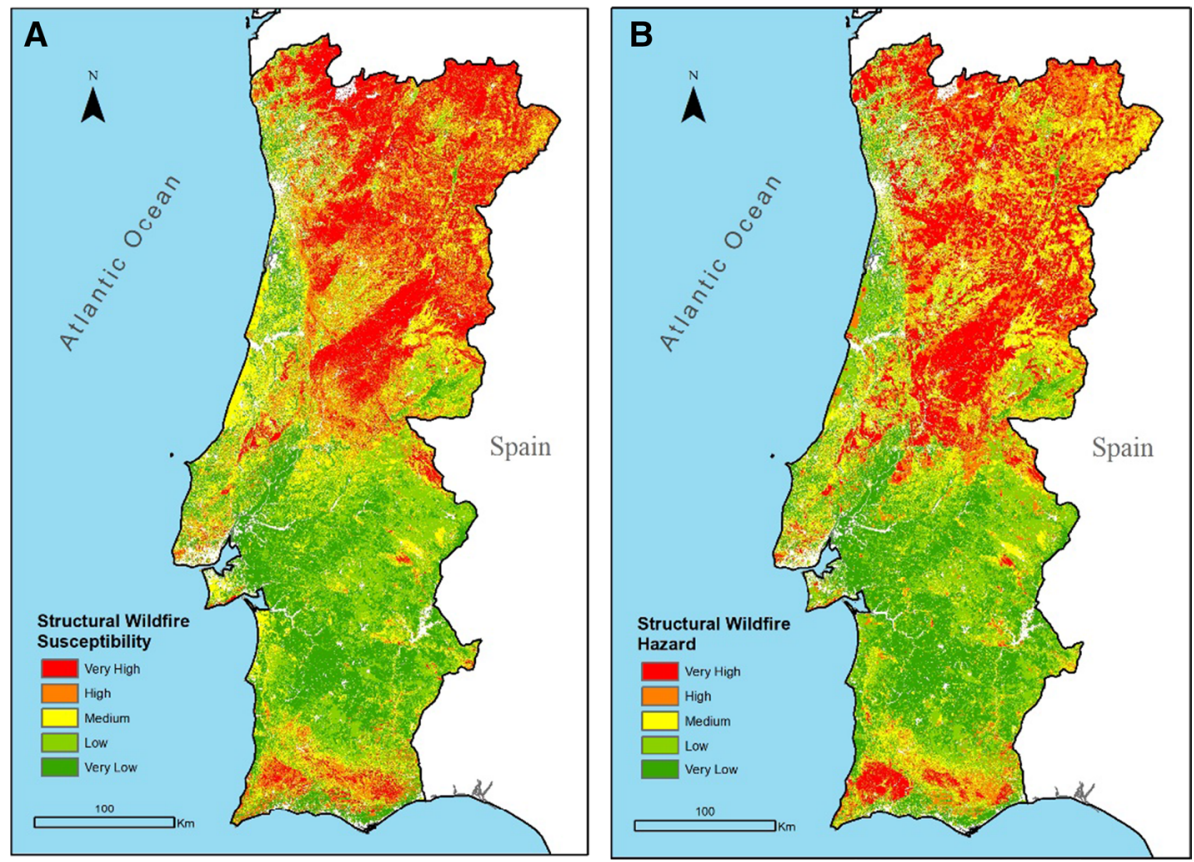

Fig. 9 Structural wildfire susceptibility $\mathbf{A}$ and hazard $\mathbf{B}$ for mainland Portugal. Both maps are classified using quintiles

conditions and/or stormy winds have been responsible for recent wildfire disasters around the world, including Portugal (Gómez-González et al. 2018; San-Miguel-Ayanz et al. 2013b; Turco, Jerez, et al. 2019a, b). In these circumstances, favorability toward a specific land cover is reduced and nearly all land cover types can be affected (Barros and Pereira 2014), and the intensity of fires can reach extreme levels that overcome existing suppression abilities (Fernandes et al. 2016; Moreira et al. 2020). The importance of weather conditions to fire activity thus justifies their integration as complementary information to structural maps, as we attempt to do in this research. Considering the static nature of the baseline maps we use and the seasonal perspective adopted, a cumulative weather index that represents a seasonal trend was considered more suitable (Nunes et al. 2019), thereby requiring a transformation of the daily version obtained from the FWI. What the SSR maps show is the spatial incidence of the deviations in weather parameters, in relation to the average since 1995, disregarding all other factors. For this reason, the higher anomalies can be found even in areas with low probability to burn or with low susceptibility/hazard levels, meaning that, in these particular areas, the weather conditions of that spring season indicate a tendency for higher dryness levels than usual. The effects of this factor over the seasonal susceptibility and hazard maps can be observed, respectively, in Figs. 11 and 12, in which the yearly spatial patterns of elevated susceptibility and hazard largely follow the yearly SSR distribution (Fig. 10). 

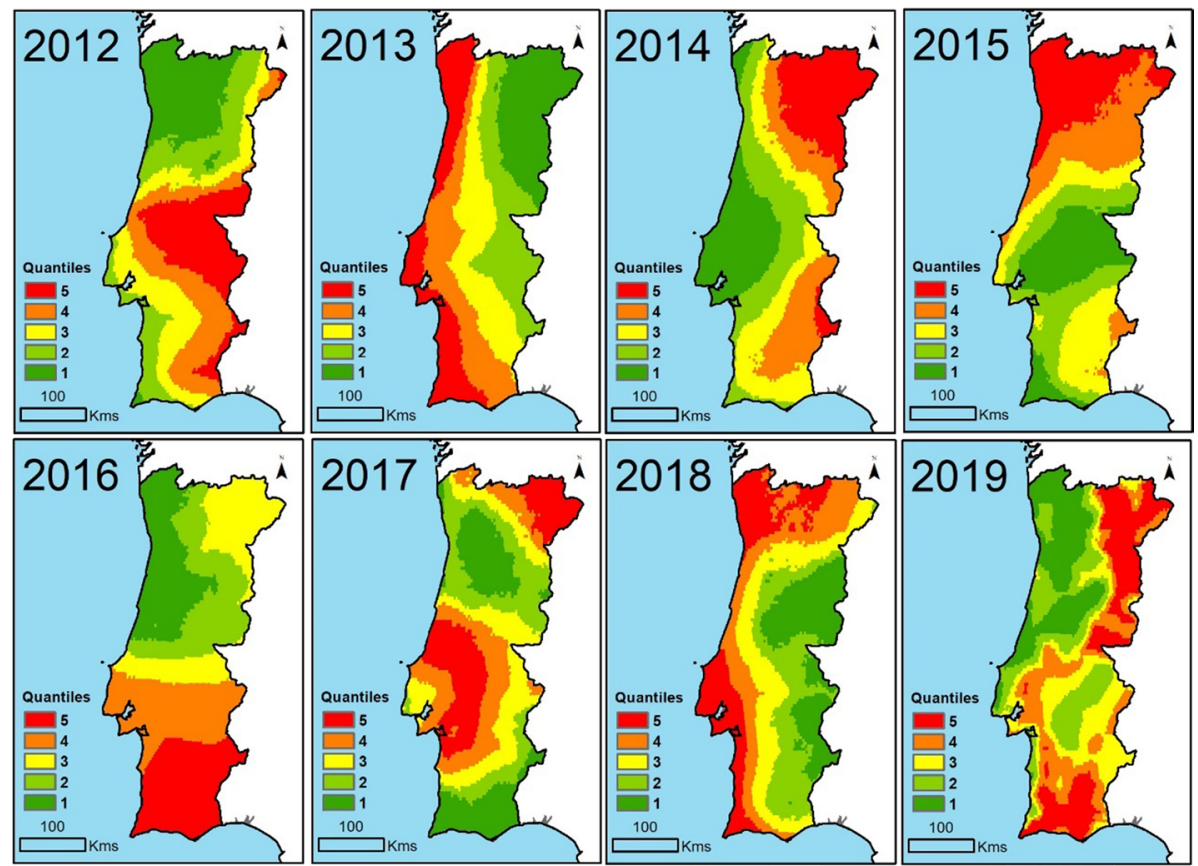

Fig. 10 Yearly seasonal severity rating (SSR) for the validation period 2012-2019. Classified using quintiles
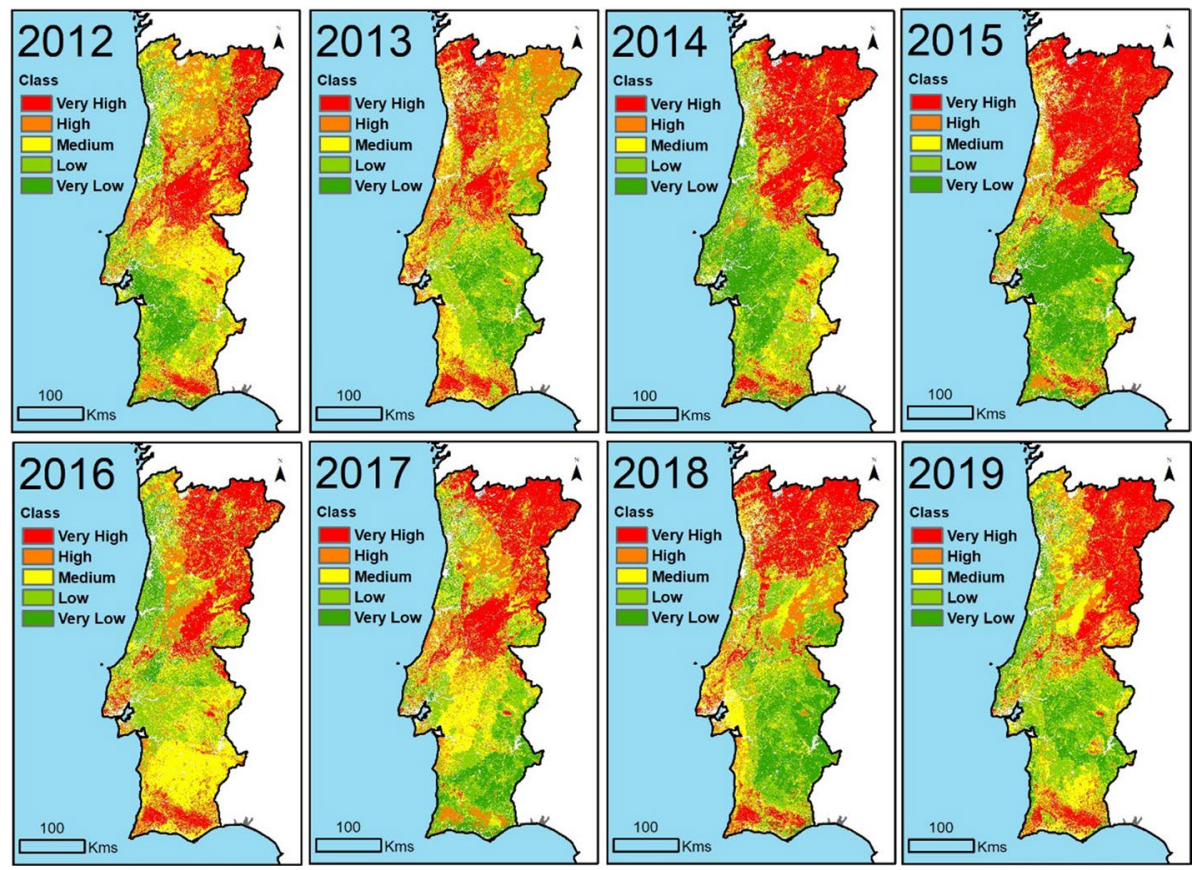

Fig. 11 Yearly seasonal susceptibility for the validation period 2012-2019 

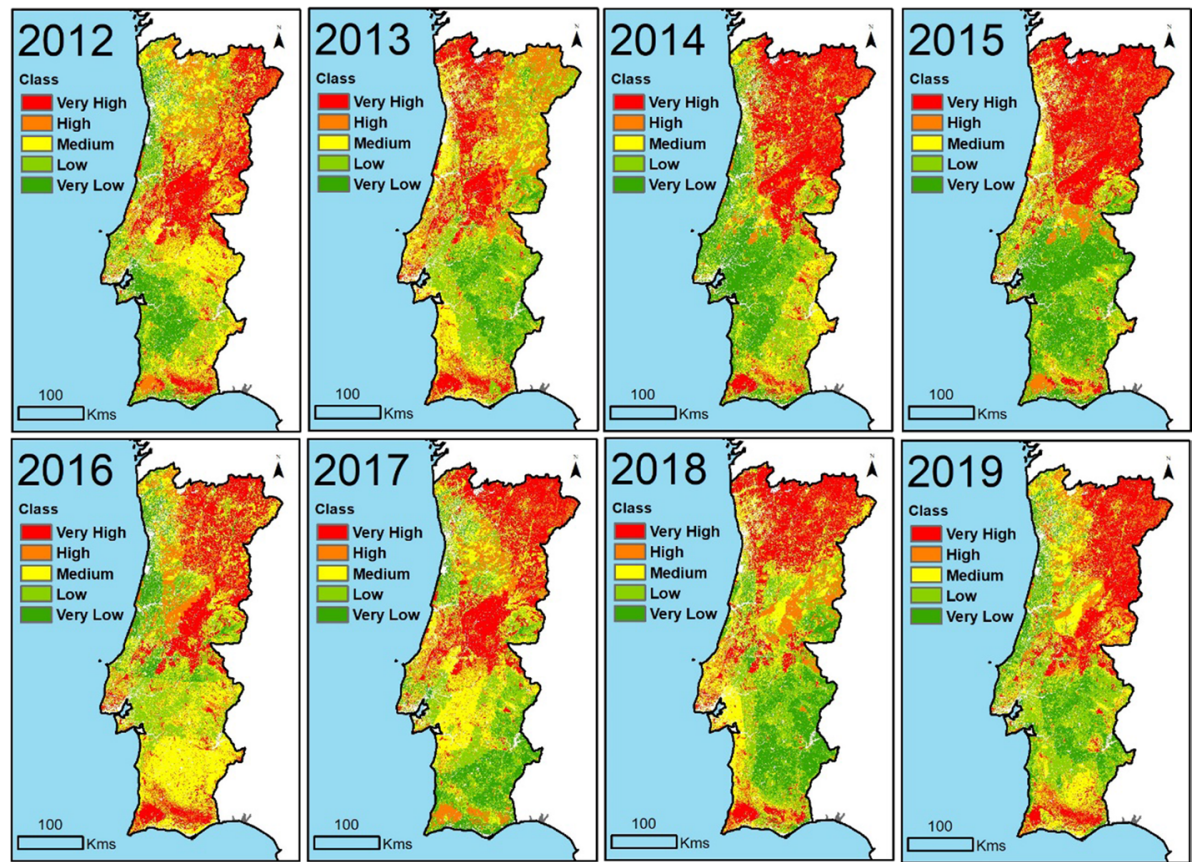

Fig. 12 Yearly seasonal hazard for the validation period 2012-2019

\subsection{Seasonal versus structural approach}

Between 2012 and 2019, the year with higher burned area in summer season was 2017, followed by the year 2016 (Table 5). Conversely, the years of 2014 and 2012 burned the least.

Focusing solely on the highest class (Very High), the analysis of the susceptibility models shows that the percentage of burnt area predicted was $10 \%$ higher for the seasonal approach (SeaA) (Table 6). The SeaA had a greater predictive capacity than the structural approach (StrA) in 6 out of the 8 validation years. If we consider the two highest classes (High and Very High) jointly, the SeaA only shows a greater predictive capacity than the structural one in half of the validation period, predicting on average less $0.7 \%$. A yearby-year analysis draws attention to 2016, in which the differences in predictive capacity between both approaches (favorable to the structural one) are more than double the highest value of all the remaining years. This suggests the anomalous character of the year 2016, without which the average differences in predictive capacity would be $17.2 \%$ for the class very high, and $3.2 \%$ for the two highest classes combined, both values in favor of the SeaA.

The comparison of the predictive capacity is complemented by the comparison of the effectiveness ratio. Considering the class very high, the SeaA was more effective in half of the years (Table 7). When the two highest classes are considered together, the SeaA was only more effective in 2 out of 8 years. In both cases, the average difference in effectiveness between the two approaches is slightly in favor of the structural one. However, the role of the year 2016 should be noted in this regard. In this year, the contrast in effectiveness between the two approaches, which is in favor of the StrA, is much higher than in all the remaining years. If this relatively anomalous value were not considered, the average 


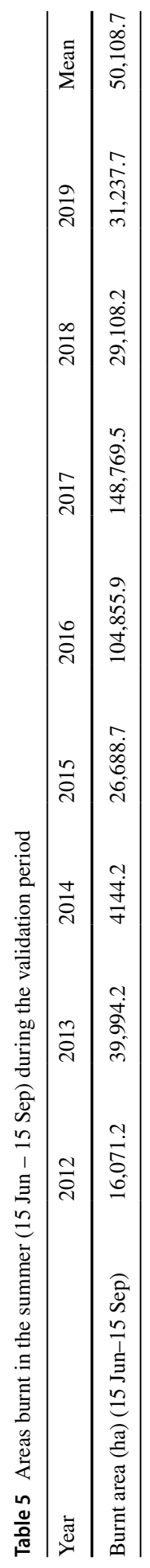


Table 6 Percentages of summer burnt area predicted by the highest and the two highest structural and seasonal wildfire susceptibility classes for the validation period 2012-2019
Table 7 Effectiveness ratio values for the highest and the two highest structural and seasonal wildfire susceptibility classes for the validation period 2012-2019. Str - Structural; Sea - Seasonal

\begin{tabular}{|c|c|c|c|c|c|c|}
\hline \multirow[b]{2}{*}{ Year } & \multicolumn{3}{|c|}{ Very high } & \multicolumn{3}{|c|}{ High + very high } \\
\hline & Str & Sea & Sea-Str & Str & Sea & Sea-Str \\
\hline 2012 & 17.5 & 46.3 & 28.8 & 62.6 & 81.0 & 18.5 \\
\hline 2013 & 61.0 & 38.0 & -23.0 & 89.1 & 81.1 & -8.0 \\
\hline 2014 & 51.0 & 74.3 & 23.3 & 78.3 & 82.7 & 4.4 \\
\hline 2015 & 58.8 & 78.8 & 20.0 & 83.4 & 86.9 & 3.5 \\
\hline 2016 & 50.2 & 9.7 & -40.4 & 80.8 & 53.9 & -26.9 \\
\hline 2017 & 52.6 & 72.6 & 19.9 & 84.9 & 84.7 & -0.3 \\
\hline 2018 & 37.7 & 76.3 & 38.6 & 78.9 & 93.0 & 14.2 \\
\hline 2019 & 31.2 & 44.1 & 12.9 & 67.8 & 57.2 & -10.6 \\
\hline Mean & 45.0 & 55.0 & 10.0 & 78.2 & 77.6 & -0.7 \\
\hline
\end{tabular}

Str-Structural; Sea-Seasonal

\begin{tabular}{lllllllr}
\hline \multirow{2}{*}{ Year } & \multicolumn{3}{l}{ Very High } & & & \multicolumn{3}{l}{ High + Very High } \\
\cline { 2 - 3 } \cline { 6 - 7 } \cline { 6 - 7 } & Str & Sea & Sea-Str & & Str & Sea & Sea-Str \\
\hline 2012 & 0.9 & 2.3 & 1.4 & & 1.6 & 1.9 & 0.3 \\
2013 & 3.1 & 2.2 & -0.9 & & 2.2 & 1.9 & -0.4 \\
2014 & 2.6 & 2.4 & -0.2 & & 2.0 & 1.9 & 0.0 \\
2015 & 3.0 & 2.4 & -0.6 & & 2.1 & 1.9 & -0.2 \\
2016 & 2.5 & 0.4 & -2.2 & & 2.0 & 1.3 & -0.7 \\
2017 & 2.7 & 3.0 & 0.3 & & 2.1 & 2.0 & -0.1 \\
2018 & 1.9 & 3.1 & 1.2 & & 2.0 & 2.3 & 0.3 \\
2019 & 1.6 & 1.9 & 0.3 & & 1.7 & 1.4 & -0.3 \\
Mean & 2.3 & 2.2 & -0.1 & & 2.0 & 1.8 & -0.1 \\
\hline
\end{tabular}

\begin{tabular}{lllllllr}
\hline \multirow{2}{*}{ Year } & \multicolumn{2}{l}{ Very High } & & & \multicolumn{3}{l}{ High + Very High } \\
\cline { 7 - 8 } & Str & Sea & Sea-Str & & Str & Sea & Sea-Str \\
\hline 2012 & 46.5 & 61.8 & 15.3 & & 79.3 & 84.1 & 4.8 \\
2013 & 64.8 & 41.6 & -23.2 & & 91.0 & 80.1 & -10.8 \\
2014 & 67.0 & 79.5 & 12.4 & & 83.0 & 85.7 & 2.7 \\
2015 & 74.3 & 85.2 & 10.8 & & 87.3 & 89.7 & 2.4 \\
2016 & 66.7 & 10.3 & -56.4 & & 85.1 & 56.0 & -29.1 \\
2017 & 67.1 & 75.2 & 8.1 & & 88.1 & 86.5 & -1.6 \\
2018 & 71.7 & 91.7 & 20.0 & & 94.2 & 97.5 & 3.3 \\
2019 & 54.4 & 54.6 & 0.1 & & 81.3 & 71.6 & -9.7 \\
Mean & 64.1 & 62.5 & -1.6 & & 86.2 & 81.4 & -4.8 \\
\hline
\end{tabular}

Str-Structural; Sea-Seasonal
Table 8 Percentages of summer burnt area predicted by the highest and the two highest structural and seasonal wildfire hazard classes for the validation period 2012-2019

difference in effectiveness would be of 0.2 in favor of the SeaA for the class very high, while remaining 0.1 in favor of the structural one for the two highest classes.

The results obtained for wildfire hazard (Table 8) show a higher predictive capacity in both approaches than that observed for susceptibility. This is necessarily a consequence of 
the inclusion of burn probability in the hazard model (Fig. 2), the only methodological difference between both indicators. The comparison between the results obtained by the StrA and the SeaA reveals mostly similar patterns to those observed for susceptibility.

In the class very high, the SeaA showed a higher predictive capacity in 6 out of 8 years, similarly to what was described for wildfire susceptibility. The average difference in percentage of burnt area predicted, however, is in favor of the StrA. This results to a large degree from the value of 2016, in which this difference (56.4\% in favor of the StrA) is more than double the highest difference among all the remaining years, confirming this year's anomalous character. If 2016 were not considered, the average difference in percentage of burnt area predicted for the remaining seven years would be $6.2 \%$ in favor of the SeaA.

If we focus on the two highest classes together (Table 8), the SeaA shows a higher predictive capacity than the StrA only in half of the years (similarly to what was described for susceptibility). The average difference between percentages of predicted burnt area is $4.8 \%$ in favor of the StrA, once more with an important influence from the year of 2016. The average value would nonetheless be in favor of the StrA (by 1.3\%), even if this year were not considered.

Regarding effectiveness (Table 9), the SeaA was less effective in 6 out of 8 years, both for the class very high and for the two highest classes together. The average differences in effectiveness between both approaches are favorable to the StrA.

In a general perspective, when the two highest classes (High and Very High) are considered together, results show that the inclusion of a seasonal dimension only benefits the baseline structural approach to wildfire hazard and susceptibility in certain years, being detrimental in others. Notably, the latter correspond precisely to those years with larger burnt area in summer (2013, 2016, 2017 and 2019, Table 5), both for susceptibility and hazard.

Overall, average results for the whole of the validation period are not in favor of the SeaA. Nevertheless, it is worth highlighting that these results were influenced to a large degree by the year 2016, which was characterized by the largest contrasts in predictive capacity between both approaches by far, both regarding susceptibility (26.9\%) and hazard $(29.1 \%)$. The influence of this anomalous year would be reduced if a longer validation period had been available. If we focus our attention solely on the highest class (Very High), that extends over $20 \%$ of mainland Portugal in the structural maps, results show that the addition of a seasonal dimension to the structural wildfire susceptibility and hazard models increased their predictive capacity in $75 \%$ of the validation years (6 out of 8 ). It is

Table 9 Effectiveness ratio values for the highest and the two highest structural and seasonal wildfire hazard classes for the validation period 2012-2019

\begin{tabular}{llllllll}
\hline \multirow{2}{*}{ Year } & \multicolumn{2}{l}{ Very High } & & & \multicolumn{2}{l}{ High+ Very High } \\
\cline { 2 - 3 } \cline { 6 - 7 } & Str & Sea & Sea-Str & & Str & Sea & Sea-Str \\
\hline 2012 & 2.4 & 3.0 & 0.6 & & 2.0 & 2.1 & 0.1 \\
2013 & 3.3 & 2.3 & -1.0 & & 2.3 & 2.0 & -0.3 \\
2014 & 3.4 & 2.7 & -0.7 & & 2.1 & 1.9 & -0.1 \\
2015 & 3.8 & 2.7 & -1.0 & & 2.2 & 1.9 & -0.3 \\
2016 & 3.4 & 0.4 & -3.0 & & 2.1 & 1.4 & -0.8 \\
2017 & 3.4 & 3.0 & -0.4 & & 2.2 & 2.1 & -0.2 \\
2018 & 3.6 & 3.9 & 0.2 & & 2.4 & 2.5 & 0.1 \\
2019 & 2.8 & 2.3 & -0.4 & & 2.1 & 1.7 & -0.3 \\
Mean & 3.2 & 2.5 & -0.7 & & 2.2 & 1.9 & -0.2 \\
\hline
\end{tabular}

Str - Structural; Sea - Seasonal 
therefore only in the very most susceptible/hazardous areas of the country that this seasonal approach presents clear advantages. Its lower average effectiveness (Tables 7 and 9) shows that this higher predictive capacity partially results from a larger area being classified with very high susceptibility/hazard in the seasonal model, eventually including a higher proportion of non-burnt pixels, together with burned ones. That is, even if the seasonal model is able to predict more burned areas, the level of efficiency is reduced if the high and very high classes in the model also include a larger proportion of non-burned areas.

Overall, these results suggest that the seasonal approach can find application as a tool for supporting the pre-positioning of firefighting means ahead of the summer season. Each year, at the end of spring, the spatial allocation of the limited available means of early detection and suppression can be prioritized by the responsible authorities to the areas included in the highest seasonal susceptibility or hazard class for the following summer. This would ensure that, in most of the years, the areas where the threat of wildfire is greatest would be more closely monitored and capable of a quicker response, expectedly leading to a reduction in annual burnt areas.

\subsubsection{The effect of the seasonal variables in the predictive capacity of the baseline model}

Our results suggest that both seasonal factors tested individually had an effect in the predictive capacity of the seasonal model, including the reduction verified in the years 2013, 2016, 2017 and 2019, as compared to the structural approach.

Table 10 shows that the highest values of overlay between areas burnt in the summer and in the previous year were recorded in three of these years (2013, 2016 and 2017), distinguishing them from all others. In these years, therefore, fuel scarcity resulting from previous wildfires had a relatively weak effect in preventing burned area in the summer. The opposite, however, happened in 2019 , in which the SeaA showed a relatively low predictive capacity despite that none of the area burnt in the summer was burnt the previous year.

Regarding the role of meteorologically induced flammability, the years 2013, 2016 and 2019 registered over $60 \%$ of all summer burnt areas in the lowest SSR classes, with the year 2017 having a lower value of $26.6 \%$ (Table 11) These results indicate that this seasonal variable was, at the individual level, a poor predictor of the extent of area burnt dur-

Table 10 Percentage of summer burnt area also burnt in the previous year, per year of the validation period. The four years characterized by a lower predictive capacity of the seasonal approach in comparison with the structural approach are highlighted in bold

\begin{tabular}{ll}
\hline Year & $\begin{array}{l}\text { \% Com- } \\
\text { mon burnt } \\
\text { area }\end{array}$ \\
\hline 2012 & 0.18 \\
$\mathbf{2 0 1 3}$ & $\mathbf{0 . 9 4}$ \\
2014 & 0.30 \\
2015 & 0.04 \\
$\mathbf{2 0 1 6}$ & $\mathbf{1 . 6 4}$ \\
$\mathbf{2 0 1 7}$ & $\mathbf{0 . 9 9}$ \\
2018 & 0.02 \\
$\mathbf{2 0 1 9}$ & $\mathbf{0}$ \\
\hline
\end{tabular}

ing the summer. 
Table 11 Percentage of summer burnt area per class of seasonal severity ratio, per year of the validation period. The four years characterized by a lower predictive capacity of the seasonal approach in comparison with the structural approach are highlighted in bold. The cumulative percentages of burnt area in the two lowest SSR classes are shown in the bottom row

\begin{tabular}{lrrrrrrrr}
\hline SSR & 2012 & $\mathbf{2 0 1 3}$ & 2014 & 2015 & $\mathbf{2 0 1 6}$ & $\mathbf{2 0 1 7}$ & 2018 & $\mathbf{2 0 1 9}$ \\
\hline 1 & 4.8 & $\mathbf{4 5 . 8}$ & 4.9 & 3.8 & $\mathbf{7 6 . 6}$ & $\mathbf{8 . 4}$ & 2.5 & $\mathbf{2 0 . 3}$ \\
2 & 24.7 & $\mathbf{1 5 . 1}$ & 7.3 & 5.1 & $\mathbf{1 7 . 4}$ & $\mathbf{1 8 . 2}$ & 0.0 & $\mathbf{4 3 . 3}$ \\
3 & 12.8 & $\mathbf{1 3 . 5}$ & 17.5 & 15.8 & $\mathbf{3 . 6}$ & $\mathbf{3 2 . 6}$ & 0.3 & $\mathbf{1 0 . 8}$ \\
4 & 16.9 & $\mathbf{6 . 0}$ & 31.5 & 41.3 & $\mathbf{2 . 3}$ & $\mathbf{2 8 . 8}$ & 78.2 & $\mathbf{7 . 8}$ \\
5 & 40.9 & $\mathbf{1 9 . 7}$ & 38.8 & 34.0 & $\mathbf{0 . 1}$ & $\mathbf{1 2 . 0}$ & 19.0 & $\mathbf{1 7 . 9}$ \\
$1+2$ & 29.5 & $\mathbf{6 0 . 9}$ & 12.2 & 8.9 & $\mathbf{9 4 . 0}$ & $\mathbf{2 6 . 6}$ & 2.5 & $\mathbf{6 3 . 6}$ \\
\hline
\end{tabular}

Overall, the four years in which the seasonal model showed a lower predictive capacity than the structural one were marked by a reduced capacity on the part of two of the three seasonal variables to predict the areas burnt. It is likely that in these specific years the burnt area patterns resulted to a higher degree from structural factors and, possibly, from other factors that were not considered in this work. Among these four years, 2016 clearly stands out as the one in which the contrasts between burnt areas predicted by the seasonal variables and those actually burnt are greatest. It registered $94 \%$ of all burnt area occurring in areas classified in the two lowest SSR classes (Table 11), as well as the maximum percentage of area burnt in two successive years within the validation period (Table 10). The complexity inherent to the phenomenon of wildfire allows for various possible explanations for this anomalous year, such as the effect of wind or other atmospheric parameters during the wildfires, increases in the number of ignitions, limitations in suppression abilities, fire propagation to areas of low accessibility, or particularly hot and dry summer conditions (inducing high fuel flammability even in years of low SSR in spring). Among these, the latter are confirmed by the monthly climatological bulletins issued by the Portuguese Institute of the Sea and Atmosphere (IPMA), which identify 2016 as the year with the $2^{\text {nd }}$ warmest July since 1931 and the $5^{\text {th }}$ warmest August (considering mean daily temperature values) (IPMA, 2016b, 2016a). These abnormally warm conditions can have, therefore, enabled the occurrence of wildfires even in areas that are usually less fire-prone. Other authors have found that, in most Mediterranean areas, antecedent climate conditions play a relatively minor role in fire occurrence, in comparison with drought conditions felt in the same summer (Turco et al. 2017). Drought conditions play a crucial role in the occurrence of large wildfires, as it has been found for Portugal (J. Parente et al. 2019; Turco, Jerez et al. 2019a, b) and elsewhere (Littell et al. 2016; Ruffault et al. 2018; Russo et al. 2017). Moreover, other authors suggested that fire size is controlled by fuel moisture content only until a certain threshold of dryness is reached, and depending on fuel availability (Loepfe et al. 2014). When exceptional weather conditions feed very large fires, firefighting capabilities can be surpassed; in a study done in Catalonia, this was verified in particular for windy conditions, whereas heat situations could be managed (Duane and Brotons, 2018). The fact that the four years in which the predictive ability of the seasonal model was lower have recorded the largest burnt areas in the 8-year validation period (Table 5) also suggests that, when wildfires acquire a certain dimension and severity, the control exerted over their behavior by the adopted seasonal variables diminishes. 
The analysis did not include data regarding suppression or specific fire management measures that could be applied before summer and influence firefighting activities and the dimension of wildfires. It is also noteworthy that the maps of yearly burnt areas used to produce the structural maps do not discriminate the exact date of occurrence of each wildfire. This implies that at least a part of the wildfires does not correspond to the summer wildfires which these maps are intended to predict. This was unavoidable because, in Portugal, state-produced burnt area mapping only discriminates the date of occurrence of wildfires since 2012. Although most damage takes place during the summer, it is expectable that the predictive capacity of all the models would increase if all burnt area data used for modeling and independent validation were limited to the summer period. Another limitation is that the results were influenced to a degree by the relatively small number of years in the validation period (eight), which was determined by the prior unavailability of data on summer wildfires. This limitation found expression in the effect of the anomalous year 2016, influencing the average results in favor of the structural approach.

\section{Conclusions}

An innovative methodology was proposed to build upon well-known structural wildfire susceptibility and hazard models by integrating them with a set of three seasonal variables, thus adapting them to the specificity of summer wildfires (June 15-September 15). This integration increased their capacity to predict summer wildfires in $75 \%$ of the validation period (2012-2019) when only the highest class (Very High) is considered. This result demonstrates that the described seasonal approach is a valuable addition to the structural wildfire susceptibility and hazard maps when the purpose is predicting which areas will burn in the summer from among the areas most likely to burn in the first place.

On the other hand, when the two highest classes (High and Very High) are considered together, gains in predictive capacity only occur in half of the validation years, with the average values being slightly in favor of the structural approach. Overall, in some years, the spatial patterns of area burnt in summer are more determined by structural factors, and possibly by other factors not considered in this work, than by the three adopted seasonal factors. Accordingly, in the years when the predictive ability of the seasonal model did not improve with regard to the structural one, the seasonal variables, namely fuel scarcity and meteorologically induced flammability, were shown to be relatively poor predictors of the spatial patterns of burnt area occurred in summertime.

Our results suggest several directions for future work. The first is to employ a longer validation period, which was impossible in this work due to data unavailability, and thus assess unequivocally how frequent are the years in which the seasonal variables improve or reduce the models' predictive capacity, while decreasing the effect of outliers. The second is to employ burnt area data relative to the summer period both for modeling and validation. Due to data limitations, the structural susceptibility and hazard maps were constructed using historical annual burn data (1975-2011) that do not discriminate summer wildfires from the remaining.

A third direction is to assess whether different seasonal variables can be employed with better results. For example, the choice of a period of 10 years without burning as an indicator of fuel overabundance was based on the mean recovery period of short-rotation forests and the expected fuel accumulation required to feed very intense fires and should be 
eventually compared with other periods. Finally, a fourth direction is to experiment other methods for combining the seasonal variables with the structural susceptibility and hazard models.

The results obtained suggest that the seasonal approach can find valuable application as a tool for supporting the pre-positioning of firefighting means ahead of the summer season. By better predicting, in most of the years, which areas in the highest susceptibility or hazard class will burn, this approach can help to optimize the management of limited human and material resources, assigning them to where the threat of wildfire is greatest.

Acknowledgments This research was undertaken in the context of the project People\&Fire, funded by the Portuguese Foundation for Science and Technology under grant PCIF/AGT/0136/2017, and by the Research Unit (UIDB/00295/2020 and UIDP/00295/2020).

Open Access This article is licensed under a Creative Commons Attribution 4.0 International License, which permits use, sharing, adaptation, distribution and reproduction in any medium or format, as long as you give appropriate credit to the original author(s) and the source, provide a link to the Creative Commons licence, and indicate if changes were made. The images or other third party material in this article are included in the article's Creative Commons licence, unless indicated otherwise in a credit line to the material. If material is not included in the article's Creative Commons licence and your intended use is not permitted by statutory regulation or exceeds the permitted use, you will need to obtain permission directly from the copyright holder. To view a copy of this licence, visit http://creativecommons.org/licenses/by/4.0/.

\section{References}

Arndt N, Vacik H, Koch V, Arpaci A, Gossow H (2013) Modeling human-caused forest fire ignition for assessing forest fire danger in Austria. IForest 6(6):315-325. https://doi.org/10.3832/ifor0936-006

Arpaci A, Malowerschnig B, Sass O, Vacik H (2014) Using multi variate data mining techniques for estimating fire susceptibility of Tyrolean forests. Appl Geogr 53:258-270. https://doi.org/10.1016/j.apgeo g.2014.05.015

Bachmann A, \& Allgöwer B (1999). The need for a consistent wildfire risk terminology. Joint Fire Science Conference and Workshop, Boise, Idaho.

Barros AMG, Pereira JMC (2014) Wildfire selectivity for land cover type: does size matter? PLoS ONE 9(1):e84760. https://doi.org/10.1371/journal.pone.0084760

Bergonse R, Bidarra J (2010) Probabilidade bayesiana e regressão logística na avaliação da susceptibilidade à ocorrência de incêndios de grande magnitude. Finisterra, 45(89):79-104. https://doi.org/10.18055/ finis 1353

Beverly JL, Herd EPK, Conner JCR (2009) Modeling fire susceptibility in west central Alberta. Canada Forest Ecol Manage 258(7):1465-1478. https://doi.org/10.1016/j.foreco.2009.06.052

Botequim B, Fernandes PM, Garcia-Gonzalo J, Silva A, Borges JG (2017) Coupling fire behaviour modelling and stand characteristics to assess and mitigate fire hazard in a maritime pine landscape in Portugal. Eur J Forest Res 136(3):527-542. https://doi.org/10.1007/s10342-017-1050-7

Calheiros T, Nunes JP, Pereira MG (2020) Recent evolution of spatial and temporal patterns of burnt areas and fire weather risk in the Iberian Peninsula. Agricultural and Forest Meteorology, 287(July 2019), 107923. https://doi.org/10.1016/j.agrformet.2020.107923

Calviño-Cancela M, Chas-Amil ML, García-Martínez ED, Touza J (2017) Interacting effects of topography, vegetation, human activities and wildland-urban interfaces on wildfire ignition risk. For Ecol Manage 397:10-17. https://doi.org/10.1016/j.foreco.2017.04.033

Cao Y, Wang M, Liu K (2017) Wildfire susceptibility assessment in Southern China: a comparison of multiple methods. Int J Disaster Risk Sci 8(2):164-181. https://doi.org/10.1007/s13753-017-0129-6

Carmo M, Moreira F, Casimiro P, Vaz P (2011) Land use and topography influences on wildfire occurrence in northern Portugal. Landscape Urban Plan 100(1-2):169-176. https://doi.org/10.1016/j.landurbpla n.2010.11.017

Carvalho A, Flannigan MD, Logan K, Miranda AI, Borrego C (2008) Fire activity in Portugal and its relationship to weather and the Canadian fire weather index system. Int J Wildland Fire 17(3):328-338. https://doi.org/10.1071/WF07014 
Chung CJF, Fabbri AG (2003) Validation of spatial prediction models for landslide hazard mapping. Nat Hazards 30(3):451-472. https://doi.org/10.1023/B:NHAZ.0000007172.62651.2b

Chuvieco E, Aguado I, Yebra M, Nieto H, Salas J, Martín MP, Vilar L, Martínez J, Martín S, Ibarra P, de la Riva J, Baeza J, Rodríguez F, Molina JR, Herrera MA, Zamora R (2010) Development of a framework for fire risk assessment using remote sensing and geographic information system technologies. Ecol Model 221(1):46-58. https://doi.org/10.1016/j.ecolmodel.2008.11.017

Costafreda-Aumedes S, Comas C, Vega-Garcia C (2017) Human-caused fire occurrence modelling in perspective: a review. Int J Wildland Fire 26(12):983. https://doi.org/10.1071/wf17026

Dee DP, Uppala SM, Simmons AJ, Berrisford P, Poli P, Kobayashi S, Andrae U, Balmaseda MA, Balsamo G, Bauer P, Bechtold P, Beljaars ACM, van de Berg L, Bidlot J, Bormann N, Delsol C, Dragani R, Fuentes M, Geer AJ, Vitart F (2011) The ERA-interim reanalysis: configuration and performance of the data assimilation system. Quart J Royal Meteorol Soc 137(656):553-597. https://doi.org/10.1002/ qj. 828

DuaneA, \& Brotons L (2018). Synoptic weather conditions and changing fire regimes in a Mediterranean environment. Agricultural and Forest Meteorology, 253-254(August 2017), 190-202. https://doi. org/https://doi.org/10.1016/j.agrformet.2018.02.014

Epifânio B, Zêzere JL, Neves M (2014) Susceptibility assessment to different types of landslides in the coastal cliffs of Lourinhã (Central Portugal). J Sea Res. https://doi.org/10.1016/j.seares.2014.04.006

EUMETSAT, C. group for meteorological satellites. (1999). EUMETSAT: LRIT/HRIT Global Specification.

Fernandes PM (2009) Combining forest structure data and fuel modelling to classify fire hazard in Portugal. Ann For Sci 66(4):415-415. https://doi.org/10.1051/forest/2009013

Fernandes P, Luz A, Loureiro C, Ferreira-Godinho P, Botelho H (2006) Fuel modelling and fire hazard assessment based on data from the Portuguese national forest inventory. For Ecol Manage 234:S229. https://doi.org/10.1016/j.foreco.2006.08.256

Fernandes PM, Loureiro C, Guiomar N, Pezzatti GB, Manso FT, Lopes L (2014) The dynamics and drivers of fuel and fire in the Portuguese public forest. J Environ Manage 146:373-382. https://doi. org/10.1016/j.jenvman.2014.07.049

Fernandes PM, Monteiro-Henriques T, Guiomar N, Loureiro C, Barros AMG (2016) Bottom-up variables govern large-fire size in Portugal. Ecosystems 19(8):1362-1375. https://doi.org/10.1007/s1002 1-016-0010-2

Gómez-González S, Ojeda F, Fernandes PM (2018) Portugal and Chile: Longing for sustainable forestry while rising from the ashes. In Environmental Science and Policy (Vol. 81, Issue July 2017, pp. 104107). Elsevier. https://doi.org/https://doi.org/10.1016/j.envsci.2017.11.006

IPMA. (2016a). Boletim Climatológico Agosto 2016. Portugal Continental. https://www.ipma.pt/resou rces.www/docs/im.publicacoes/edicoes.online/20160909/oZCXbBshSWinamgtWDwc/cli_20160 801_20160831_pcl_mm_co_pt.pdf

IPMA. (2016b). Boletim Climatológico Julho 2016. Portugal Continental. https://www.ipma.pt/resou rces.www/docs/im.publicacoes/edicoes.online/20160804/ZtQLGjZAOdMxcajQukNP/cli_20160 701_20160731_pcl_mm_co_pt.pdf

Jolly WM, Cochrane MA, Freeborn PH, Holden ZA, Brown TJ, Williamson GJ, Bowman DMJSJS (2015) Climate-induced variations in global wildfire danger from 1979 to 2013. Nat Commun 6(May):1-11. https://doi.org/10.1038/ncomms8537

Julião R, Nery F, Ribeiro J, Branco M, Zêzere J (2009). Guia metodológico para a produção de cartografia municipal de risco e para a criação de sistemas de informação geográfica (SIG) de base municipal. In Autoridade Nacional de Autoridade Nacional de Protecção Civil.

Lasanta T, Khorchani M, Pérez-Cabello F, Errea P, Sáenz-Blanco R, Nadal-Romero E (2018) Clearing shrubland and extensive livestock farming: active prevention to control wildfires in the Mediterranean mountains. J Environ Manage 227(August):256-266. https://doi.org/10.1016/j.jenvman.2018.08.104

Lasslop G, Hantson S, Kloster S (2015) Influence of wind speed on the global variability of burned fraction: a global fire model's perspective. Int J Wildland Fire 24(7):989-1000

Lee S (2004) Application of likelihood ratio and logistic regression models to landslide susceptibility mapping using GIS. Environ Manage 34(2):223-232. https://doi.org/10.1007/s00267-003-0077-3

Leuenberger M, Parente J, Tonini M, Pereira MG, Kanevski M (2018) Wildfire susceptibility mapping: deterministic vs. stochastic approaches. Environ Model Software 101:194-203. https://doi. org/10.1016/j.envsoft.2017.12.019

Littell JS, Peterson DL, Riley KL, Liu Y, Luce CH (2016) A review of the relationships between drought and forest fire in the United States. Glob Change Biol 22(7):2353-2369. https://doi.org/10.1111/ gcb. 13275 
Loepfe L, Rodrigo A, Lloret F (2014) Two thresholds determine climatic control of forest fire size in Europe and northern Africa. Reg Environ Change 14(4):1395-1404. https://doi.org/10.1007/s1011 3-013-0583-7

López AS, San-Miguel-Ayanz J, Burgan RE (2002) Integration of satellite sensor data, fuel type maps and meteorological observations for evaluation of forest fire risk at the pan-European scale. Int J Remote Sens 23(13):2713-2719. https://doi.org/10.1080/01431160110107761

Marcos R, Turco M, Bedía J, Llasat MC, Provenzale A (2015) Seasonal predictability of summer fires in a Mediterranean environment. Int J Wildland Fire 24(8):1076. https://doi.org/10.1071/wf15079

Moreira F, Rego FC, Ferreira PG (2001) Temporal (1958-1995) pattern of change in a cultural landscape of northwestern Portugal: implications for fire occurrence. Landscape Ecol 16(6):557-567. https://doi. org/10.1023/A:1013130528470

Moreira F, Vaz P, Catry F, Silva JS (2009) Regional variations in wildfire susceptibility of land-cover types in Portugal: implications for landscape management to minimize fire hazard. Int $\mathrm{J}$ Wildland Fire 18(5):563-574. https://doi.org/10.1071/WF07098

Moreira F, Viedma O, Arianoutsou M, Curt T, Koutsias N, Rigolot E, Barbati A, Corona P, Vaz P, Xanthopoulos G, Mouillot F, Bilgili E (2011). Landscape - wildfire interactions in southern Europe: Implications for landscape management. In Journal of Environmental Management (Vol. 92, Issue 10, pp. 2389-2402). https://doi.org/https://doi.org/10.1016/j.jenvman.2011.06.028

Moreira F, Ascoli D, Safford H, Adams MA, Moreno JM, Pereira JMC, Catry FX, Armesto J, Bond W, González ME, Curt T, Koutsias N, McCaw L, Price O, Pausas JG, Rigolot E, Stephens S, Tavsanoglu C, Vallejo Fernandes VRPM (2020) Wildfire management in Mediterranean-type regions: paradigm change needed. Environ Res Lett 15(1):011001. https://doi.org/10.1088/1748-9326/ab541e

Nunes SA, Camara CC da, Turkman KF, Ermida SL, Calado T J (2014). Anticipating the severity of the fire season in Northern Portugal using statistical models based on meteorological indices of fire danger. In D. X. Viegas (Ed.), Advances in forest fire research (pp. 1634-1645). Imprensa da Universidade de Coimbra. https://doi.org/https://doi.org/10.14195/978-989-26-0884-6_180

Nunes AN, Lourenço L, Meira ACC (2016) Exploring spatial patterns and drivers of forest fires in Portugal (1980-2014). Sci Total Environ 573:1190-1202. https://doi.org/10.1016/j.scitotenv.2016.03.121

Nunes SA, Dacamara CC, Turkman KF, Calado TJ, Trigo RM, Turkman MAA (2019) Wildland fire potential outlooks for Portugal using meteorological indices of fire danger. Nat Hazards Earth Syst Sci 19(7):1459-1470. https://doi.org/10.5194/nhess-19-1459-2019

Oliveira S, Zêzere JL (2020) Assessing the biophysical and social drivers of burned area distribution at the local scale. J Environ Manage 264:110449. https://doi.org/10.1016/j.jenvman.2020.110449

Oliveira S, Oehler F, San-Miguel-Ayanz J, Camia A, Pereira JMC (2012) Modeling spatial patterns of fire occurrence in Mediterranean Europe using multiple regression and random forest. For Ecol Manage 275:117-129. https://doi.org/10.1016/j.foreco.2012.03.003

Oliveira S, Moreira F, Boca R, San-Miguel-Ayanz J, Pereira JMC (2014) Assessment of fire selectivity in relation to land cover and topography: a comparison between Southern European countries. Int J Wildland Fire 23(5):620-630. https://doi.org/10.1071/WF12053

Oliveira S, Gonçalves A, Zêzere JL (2020) Reassessing wildfire susceptibility and hazard for mainland Portugal. Sci Total Environ. https://doi.org/10.1016/j.scitotenv.2020.143121

Parente J, Pereira MG (2016) Structural fire risk: the case of Portugal. Sci Total Environ 573:883-893. https://doi.org/10.1016/j.scitotenv.2016.08.164

Parente J, Amraoui M, Menezes I, Pereira MG (2019) Drought in Portugal: current regime, comparison of indices and impacts on extreme wildfires. Sci Total Environ 685:150-173. https://doi. org/10.1016/j.scitotenv.2019.05.298

Pausas JG, Fernández-Muñoz S (2012) Fire regime changes in the Western Mediterranean Basin: from fuel-limited to drought-driven fire regime. Climatic Change 110(1-2):215-226. https://doi. org/10.1007/s10584-011-0060-6

Pereira MG, Trigo RM, Da Camara CC, Pereira JMC, Leite SM (2005) Synoptic patterns associated with large summer forest fires in Portugal. Agric For Meteorol 129(1-2):11-25. https://doi. org/10.1016/j.agrformet.2004.12.007

Pereira JMC, Carreiras JMB, Silva JMN, Vasconcelos MJ (2006) Alguns Conceitos Básicos sobre os Fogos Rurais em Portugal. In J. S. Pereira, J. M. C. Pereira, F. C. Rego, J. M. N. Silva, \& T. P. Silva (Eds.), Incêndios Florestais em Portugal: Caracterização, Impactes e Prevenção (Issue October 2017, pp. 133-161). ISAPress.

Pereira MG, Malamud BD, Trigo RM, Alves PI (2011) The history and characteristics of the 19802005 Portuguese rural fire database. Nat Hazards Earth Syst Sci 11(12):3343-3358. https://doi. org/10.5194/nhess-11-3343-2011 
Pereira MG, Calado TJ, DaCamara CC, Calheiros T (2013) Effects of regional climate change on rural fires in Portugal. Climate Res 57(3):187-200. https://doi.org/10.3354/cr01176

Peters MP, Iverson LR, Matthews SN, Prasad AM (2013) Wildfire hazard mapping: exploring site conditions in eastern US wildland-urban interfaces. Int J Wildland Fire 22(5):567-578. https://doi. org/10.1071/WF12177

Pinto MM, DaCamara CC, Trigo IF, Trigo RM, Turkman KF (2018) Fire danger rating over Mediterranean Europe based on fire radiative power derived from Meteosat. Nat Hazards Earth Syst Sci 18(2):515-529. https://doi.org/10.5194/nhess-18-515-2018

Ruffault J, Curt T, Martin-Stpaul NK, Moron V, Trigo RM (2018) Extreme wildfire events are linked to global-change-type droughts in the northern Mediterranean. Nat Hazards Earth Syst Sci 18(3):847856. https://doi.org/10.5194/nhess-18-847-2018

Russo A, Gouveia CM, Páscoa P, DaCamara CC, Sousa PM, Trigo RM (2017) Assessing the role of drought events on wildfires in the Iberian Peninsula. Agric For Meteorol 237-238:50-59. https:// doi.org/10.1016/j.agrformet.2017.01.021

San-Miguel-Ayanz J, Moreno JM, Camia A (2013) Analysis of large fires in European Mediterranean landscapes: lessons learned and perspectives. For Ecol Manage 294:11-22. https://doi.org/10.1016/j.forec o.2012.10.050

San-Miguel-Ayanz J, Moreno JM, Camia A (2013b). Analysis of large fires in European Mediterranean landscapes: Lessons learned and perspectives. In Forest Ecology and Management (Vol. 294). https:// doi.org/https://doi.org/10.1016/j.foreco.2012.10.050

San-Miguel-Ayanz J, Durrant T, Boca R, Libertá G, Branco A, De Rigo D, Ferrari D, Maianti P, Artes Vivancos T, Pfeiffer H, Loffler P, Nuijten D, Leray T, Oom JF, D. (2019) Forest fires in Europe, middle east and North Africa 2018. Publications Office of the European Union, Luxembourg. https://doi. org/10.2760/1128

Sebastián-López A, Salvador-Civil R, Gonzalo-Jiménez J, SanMiguel-Ayanz J (2008) Integration of socioeconomic and environmental variables for modelling long-term fire danger in Southern Europe. Eur J Forest Res 127(2):149-163. https://doi.org/10.1007/s10342-007-0191-5

Slocum MG, Beckage B, Platt WJ, Orzell SL, Taylor W (2010) Effect of climate on wildfire size: a crossscale analysis. Ecosystems 13(6):828-840. https://doi.org/10.1007/s10021-010-9357-y

Trigo RM, Sousa PM, Pereira MG, Rasilla D, Gouveia CM (2016) Modelling wildfire activity in Iberia with different atmospheric circulation weather types. Int J Climatol 36(7):2761-2778. https://doi. org/10.1002/joc.3749

Turco M, von Hardenberg J, AghaKouchak A, Llasat MC, Provenzale A, Trigo RM (2017) On the key role of droughts in the dynamics of summer fires in Mediterranean Europe. Sci Rep 7(81):1-10. https://doi. org/10.1038/s41598-017-00116-9

Turco M, Jerez S, Augusto S, Tarín-Carrasco P, Ratola N, Jiménez-Guerrero P, Trigo RM (2019) Climate drivers of the 2017 devastating fires in Portugal. Sci Rep 9(1):1-8. https://doi.org/10.1038/s4159 8-019-50281-2

Turco M, Marcos-Matamoros R, Castro X, Canyameras E, Llasat MC (2019) Seasonal prediction of climate-driven fire risk for decision-making and operational applications in a Mediterranean region. Sci Total Environ 676:577-583. https://doi.org/10.1016/j.scitotenv.2019.04.296

Urbieta IR, Zavala G, Bedia J, Gutiérrez JM, Miguel-Ayanz J S, Camia A, Keeley JE, Moreno JM (2015). Fire activity as a function of fire-weather seasonal severity and antecedent climate across spatial scales in southern Europe and Pacific western USA. Environmental Research Letters, 10(11). https://doi. org/https://doi.org/10.1088/1748-9326/10/11/114013

Valdez MC, Chang KT, Chen CF, Chiang SH, Santos JL (2017) Modelling the spatial variability of wildfire susceptibility in Honduras using remote sensing and geographical information systems. Geomat Nat Hazards Risk 8(2):876-892. https://doi.org/10.1080/19475705.2016.1278404

Van Wagner CE (1974). Structure of the Canadian forest fire weather index (Vol. 1333).

Van Wagner CE (1987). Development and Structure of the Canadian Forest Fire Weather Index System Forestry Technical Report $n^{\circ} 35$.

Varnes DJ (1984). Landslide hazard zonation: a review of principles and practice (No. 3).

Verde JC, Zêzere JL (2010) Assessment and validation of wildfire susceptibility and hazard in Portugal. Nat Hazards Earth Syst Sci 10(3):485-497. https://doi.org/10.5194/nhess-10-485-2010

Viedma O, Angeler DG, Moreno JM (2009) Landscape structural features control fire size in a Mediterranean forested area of central Spain. Int J Wildland Fire 18(5):575-583. https://doi.org/10.1071/WF080 30

Viegas DX (2006) Modelação do comportamento do fogo. In João Santos Pereira, J. M. C. Pereira, F. C. Rego, J. M. N. Silva, \& T. P. da Silva (Eds.), Incêndios Florestais em Portugal - Caracterização, Impactes e Prevenção (pp. 287-325). IsaPress. 
Weise DR, Zhou X, Sun L, Mahalingam S (2005) Fire spread in chaparral - “Go or no-go?” Int J Wildland Fire 14(1):99-106. https://doi.org/10.1071/WF04049

Publisher's Note Springer Nature remains neutral with regard to jurisdictional claims in published maps and institutional affiliations.

\section{Authors and Affiliations}

\section{Rafaello Bergonse $^{1} \mathbb{D}$. Sandra Oliveira ${ }^{1} \cdot$ Ana Gonçalves $^{1} \cdot$ Sílvia Nunes $^{2}$. Carlos da Câmara $^{2}$. José Luis Zêzere ${ }^{1}$}

Sandra Oliveira

sandra.oliveira1@campus.ul.pt

Ana Gonçalves

acng@campus.ul.pt

Sílvia Nunes

sanunes@fc.ul.pt

Carlos da Câmara

cdcamara@fc.ul.pt

José Luis Zêzere

zezere@campus.ul.pt

1 Centre for Geographical Studies, Universidade de Lisboa, Rua Branca Edmée Marques, Cidade Universitária, 1600-276, Lisbon, Portugal

2 Faculdade de Ciências, Instituto Dom Luiz (IDL), Universidade de Lisboa, 1749-016, Lisbon, Portugal 